\title{
Function of Membrane Rafts in Viral Lifecycles and Host Cellular Response
}

\author{
Tadanobu Takahashi and Takashi Suzuki \\ Department of Biochemistry, School of Pharmaceutical Sciences, and Global COE Program for Innovation in Human Health Sciences, \\ University of Shizuoka, Shizuoka 422-8526, Japan \\ Correspondence should be addressed to Takashi Suzuki, suzukit@u-shizuoka-ken.ac.jp
}

Received 3 August 2011; Revised 31 August 2011; Accepted 27 September 2011

Academic Editor: Brian P. Head

Copyright (๑) 2011 T. Takahashi and T. Suzuki. This is an open access article distributed under the Creative Commons Attribution License, which permits unrestricted use, distribution, and reproduction in any medium, provided the original work is properly cited.

\begin{abstract}
Membrane rafts are small $(10-200 \mathrm{~nm})$ sterol- and sphingolipid-enriched domains that compartmentalize cellular processes. Membrane rafts play an important role in viral infection cycles and viral virulence. Viruses are divided into four main classes, enveloped DNA virus, enveloped RNA virus, nonenveloped DNA virus, and nonenveloped RNA virus. General virus infection cycle is also classified into two sections, the early stage (entry process) and the late stage (assembly, budding, and release processes of virus particles). In the viral cycle, membrane rafts act as a scaffold of many cellular signal transductions, which are associated with symptoms caused by viral infections. In this paper, we describe the functions of membrane rafts in viral lifecycles and host cellular response according to each virus classification, each stage of the virus lifecycle, and each virus-induced signal transduction.
\end{abstract}

\section{Introduction}

Relationships between virus infection mechanisms and lipid rafts had often been studied in complexes with caveolae [1, 2]. Lipid rafts, membrane microdomains enriched in cholesterol, and sphingolipids represented by GM1 and globotriaosylceramide (Gb3Cer) were defined at the Keystone Symposium on Lipid Rafts and Cell Function (March 23-28, 2006 in Steamboat Springs, CO) as follows: "Membrane rafts are small (10-200 nm), heterogeneous, highly dynamic, steroland sphingolipid-enriched domains that compartmentalize cellular processes. Small rafts can sometimes be stabilized to form larger platforms through protein-protein and proteinlipid interactions." This definition led to the term "lipid raft" being discarded in favor of the term "membrane raft". The term "membrane raft" underlies the concept that both proteins and lipids, rather than solely lipid-driven interactions, play an important role in the formation of these membrane microdomains. The caveola, a cholesterol/sphingolipid-rich small pit, depression, or invagination, is a site on the cell surface that provides a platform for proteins and lipids to interact and transmit signals. In the symposium, the range of $10-200 \mathrm{~nm}$, which was adopted as the size of membrane rafts, included the upper limit on the surface of a caveola. Here, membrane rafts include caveolae [3].

Membrane rafts have been shown to be involved in the virus entry, assembly, or/and budding process in infection lifecycles of various viruses, such as retroviruses (Retroviridae), RNA viruses (Arenaviridae, Astroviridae, Bunyaviridae, Caliciviridae, Coronaviridae, Filoviridae, Flaviviridae, Orthomyxoviridae, Paramyxoviridae, Picornaviridae, Reoviridae, Rhabdoviridae, and Togaviridae), and DNA viruses (Adenoviridae, Hepadnaviridae, Herpesviridae, Papovaviridae, Parvoviridae, and Poxviridae). These studies have demonstrated the localization of viral structural proteins in membrane rafts and the effects of raft-disrupting agents, which mainly remove cholesterol from the surface membrane or inhibit the synthesis of cholesterol, on the infection and replication processes of these viruses. The virus infection process begins with attachment of the virus to specific receptors on host cell surfaces. Some RNA viruses, such as Orthomyxoviridae, Rhabdoviridae and Togaviridae family viruses, and DNA viruses, such as Adenoviridae and Papovaviridae family viruses, enter cells through an endocytic pathway and inject viral proteins and genes directly into the cytoplasm by fusion of the viral envelope with the host cellular membrane or des- 
truction of viral capsids. Other enveloped viruses, such as Paramyxoviridae family viruses, allow the viral membrane to fuse directly with the host cell surface membrane and inject the viral proteins and genes directly into the cytoplasm. Transcription and replication of DNA viruses except poxviruses generally proceed inside the nucleus, whereas those of RNA viruses except influenza virus proceed in the cytoplasm. Newly synthesized progeny viral components are transferred to organelles or the plasma membrane, resulting in formation of progeny virus particles by assembly and/or budding. Virus particles are classified by configuration of the viral outer envelope into two types, enveloped viruses (Arenaviridae, Bunyaviridae, Coronaviridae, Filoviridae, Flaviviridae, Herpesviridae, Hepadnaviridae, Orthomyxoviridae, Paramyxoviridae Poxviridae, Rhabdoviridae and Togaviridae) and nonenveloped viruses (Adenoviridae, Astroviridae, Caliciviridae, Picornaviridae, Papovaviridae, Parvoviridae and Reoviridae) (Figures 1 and 2). The envelope constructs of enveloped viruses are lipid bilayers derived from the host cellular membrane of the cell surface, Golgi body, or endoplasmic reticulum (ER), where the viruses are budded. Viral surface proteins transferred to the cell surface are buried in the viral envelope together with the lipid bilayer of the host cell surface (Figure 1). Nonenveloped viruses are generally assembled in the cytoplasm or nucleus and burst into the extracellular environment through membrane destruction from cell death (Figure 2). In this paper, recent findings on the function of membrane rafts in viral lifecycles and host cellular response are discussed.

\section{Role of Membrane Rafts in Virus Entry}

The involvement of membrane rafts in virus entry has been evaluated by the effects of raft-disrupting reagents on virus infection and by the effects of cholesterol-removing reagents such as methyl- $\beta$-cyclodextrin and cholesterol synthesis inhibitors such as nystatin. Inhibition of virus infection by cholesterol depletion is generally recovered by the addition of exogenous cholesterol without affecting virus binding to cellular receptors. Traditional examinations of membrane raft function in virus entry have been performed by biochemical methods for detection of viral proteins and viral cellular receptors within a detergent-insoluble fraction after virus attachment and during virus infection or colocalization of these proteins and receptors with specific raft markers such as caveolin-1, flotillin, and GM1. Molecular biological examinations of the role of a caveola-dependent endocytic pathway in virus entry have also been performed by inhibition of caveola formation using RNA interference (RNAi) and dominant-negative protein expression for normal caveolin1 knockdown.

\section{Entry of Enveloped Viruses}

Entry processes of enveloped viruses associated with membrane rafts have been evaluated for lymphocytic choriomeningitis virus (LCMV; Arenaviridae) [4], coronaviruses including severe acute respiratory syndrome coronavirus
(SARS-CoV) (Coronaviridae) [5-11], Ebola virus (Filoviridae) [12-14], Marburg virus (Filoviridae) [12, 15], West Nile virus (WNV; Flaviviridae) [16], dengue virus (DEN; Flaviviridae) [17-20], Japanese encephalitis virus (JEV; Flaviviridae) $[19,21]$, human hepatitis $\mathrm{C}$ virus ( $\mathrm{HCV}$; Flaviviridae) [22, 23], Epstein-Barr virus (EBV; herpesviridae) [24, 25], herpes simplex virus-1 (HSV-1; herpesviridae) [26, 27] including porcine herpesvirus-1 pseudorabies virus [28], human herpesvirus-6 (HHV-6; Herpesviridae) [29], human herpesvirus- 8 of Kaposi's sarcoma-associated herpesvirus (HHV-8; Herpesviridae) [30, 31], influenza virus (Orthomyxoviridae) [32-37], vaccinia virus (Poxviridae) [38], human immunodeficiency virus (HIV; Retroviridae) [3945], human T lymphotropic virus 1 (HTLV-1; Retroviridae) [46, 47], Semliki Forest virus (Togaviridae) [48-51], and Sindbis virus (Togaviridae) [51, 52].

The majority of enveloped viruses release viral internal genomes and proteins into the intracellular compartment through fusion processes induced by viral surface proteins between viral and cellular membranes immediately after virus attachment to receptors or the endocytic pathway.

Human coronavirus, a pathogen causing $10-30 \%$ of all common colds manifesting upper respiratory and gastrointestinal symptoms, enters cells through caveola-dependent endocytosis after attachment to the viral receptor CD13 within membrane rafts. It has been shown that virus infection is inhibited by caveola destruction using a cholesterolremoving reagent and an RNAi method for caveolin-1 [5]. Mouse hepatitis virus (MHV) of murine coronaviruses binds to nonraft membranes but moves to raft membranes for virus entry and fusion processes. Membrane rafts are not incorporated into the MHV virion and are not associated with the spike (S) protein of MHV on the Golgi body membrane, which is the site of virus assembly and budding. Membrane rafts are therefore not required for the virus release process $[6,7]$. SARS-CoV, the most extensively researched human coronavirus that causes severe acute respiratory syndrome (SARS), associates with membrane rafts as an entry platform via the viral spike (S) protein after binding to the viral receptor angiotensin-converting enzyme 2 (ACE2) within rafts of Vero E6 cells $[8,10]$. Moreover, SARS-CoV and feline infectious peritonitis virus (FIPV), a coronavirus causing lethal chronic disease in cats, enter cells through a clathrin-independent and caveola-independent pathway because both dominant-negative protein expressions of Eps15 (required for the clathrin-dependent pathway) and caveolin-1 have no effect on virus infectivity and no colocalization of caveolin-1 is observed with viral proteins during virus entry. However, inhibition of virus infection by cholesterol depletion indicates the importance of raft-mediated endocytosis for the entry process of these viruses $[9,11]$. Taken together, results of studies indicate that raft-mediated endocytosis associated with cholesterol is distinctly different from caveolin-1-dependent endocytosis.

Ebola virus and Marburg virus, two of the most pathogenic viruses in humans and nonhuman primates that cause severe hemorrhagic fever with mortality rates reaching $90 \%$, enter host cells through folate receptor- $\alpha(\mathrm{FR} \alpha)$ as a viral coreceptor, which is a glycosyl phosphatidylinositol-(GPI-) 


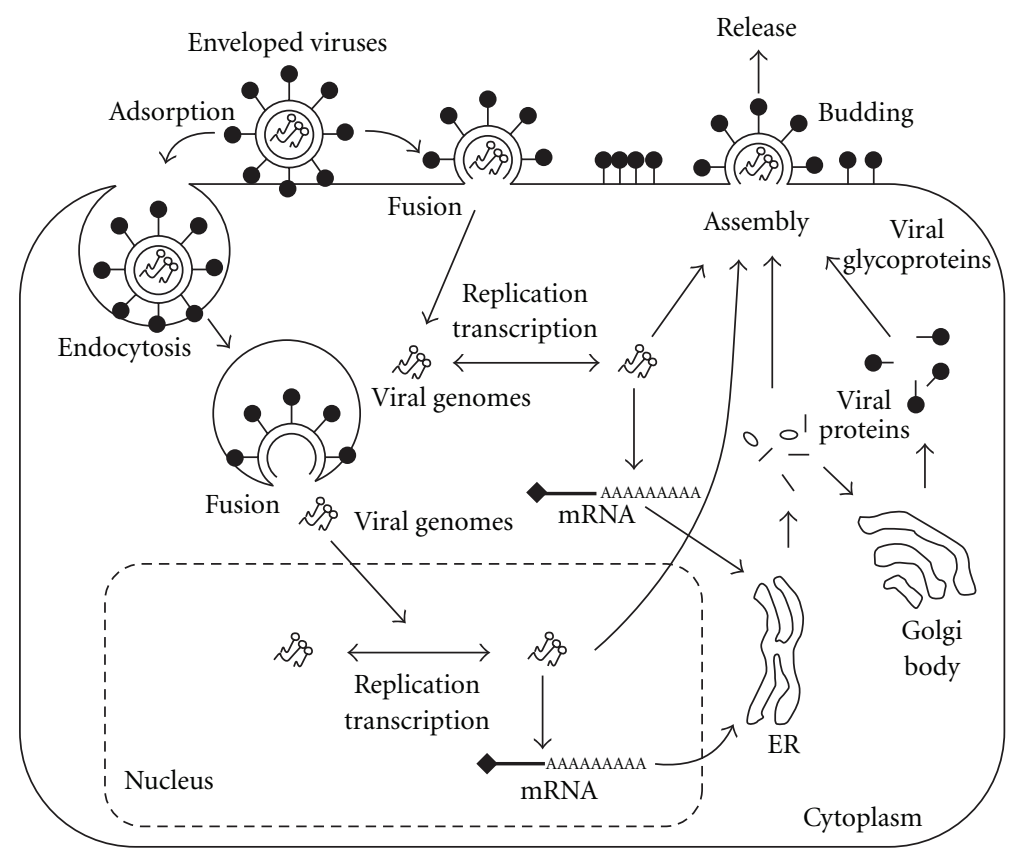

FIGURE 1: Entry, assembly, and budding processes of enveloped viruses. Some enveloped viruses, such as Orthomyxoviridae, Rhabdoviridae, and Togaviridae family viruses, are incorporated into cells through an endocytic pathway. Other enveloped viruses, such as Paramyxoviridae family viruses, are incorporated into cells through direct fusion between the viral membrane and cell surface membrane. Herpesviridae family viruses utilize both pathways. Viral genomes of enveloped RNA viruses, such as Orthomyxoviridae family viruses, and enveloped DNA viruses, such as Herpesviridae family viruses, are replicated and transcribed in the nucleus. On the other hand, viral genomes of enveloped RNA viruses, such as Paramyxoviridae family viruses, are replicated and transcribed in the cytoplasm. After assembly of viral proteins and genomes, progeny viruses are budded and then released from the cell surface membrane.

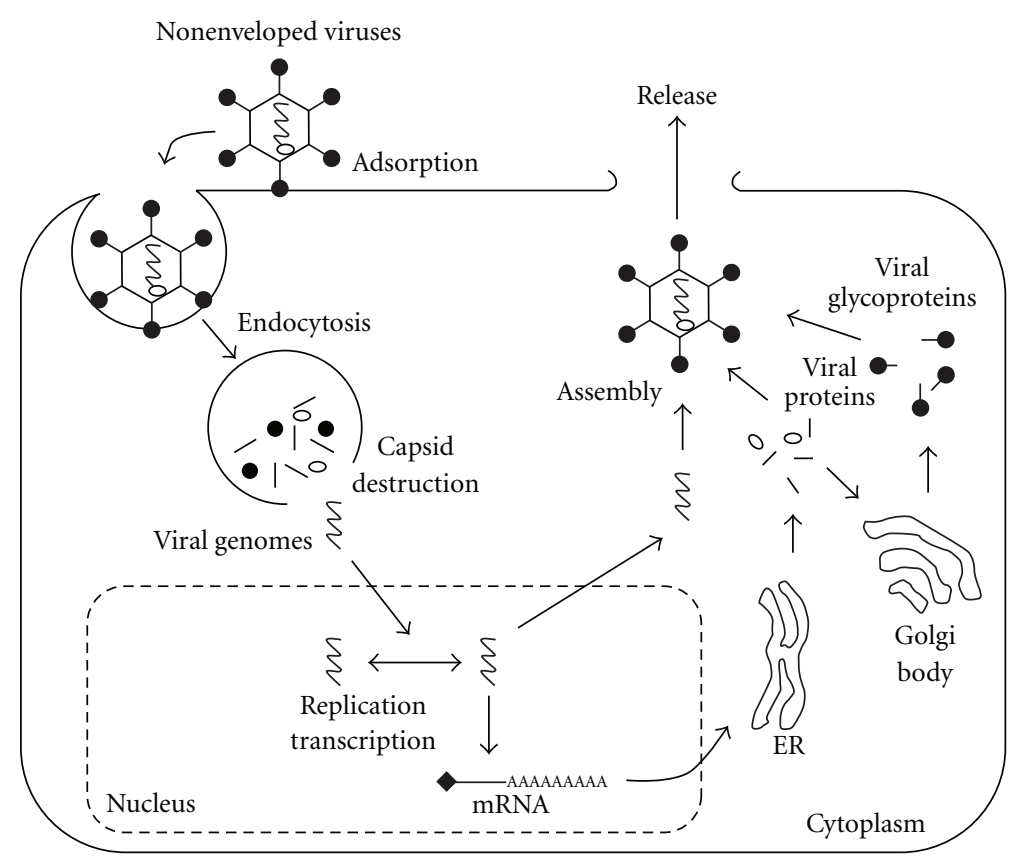

Figure 2: Entry, assembly, and budding processes of nonenveloped viruses. Nonenveloped DNA viruses, such as Adenoviridae and Papovaviridae family viruses, are incorporated into cells through endocytosis and then their viral DNA genomes are released into the cytoplasm by viral capsid destruction. Viral genomes are subjected to replication and transcription in the nucleus. After assembly of viral proteins and genomes, progeny viruses are released from cells. 
anchored protein within membrane rafts [53]. The severe pathogenesis of these viruses in humans makes studies on the infection mechanism difficult to perform using intact viruses. Results of studies using pseudotypes possessing these viral proteins suggest that filoviruses utilize acidified endosomes for vial entry [54, 55]. Inhibitory effects of a cholesterol-removing reagent and a cholesterol synthesis inhibitor on viral infectivity have demonstrated the requirement of membrane rafts in filovirus entry $[12,15]$. The entry process of pseudotypes and virus-like particles bearing glycoproteins of Zaire Ebola virus and Lake Victoria Marburg virus appears to occur through multiple pathways including dynamin-dependent (clathrin-dependent and caveoladependent endocytosis) and dynamin-independent pathways such as macropinocytosis that is enhanced by Axl, a plasma membrane-associated Tyro3/Axl/Mer (TAM) family member, although Axl is not a receptor for filoviruses [14]. Ebola fusion peptide, a hydrophobic helical domain that belongs to the GP2 membrane fusion protein of Ebola virus, is sensitive to interaction with membrane rafts, suggesting the involvement of membrane rafts in the fusion process of Ebola virus during entry into cells [13].

Flaviviruses enter cells through receptor-mediated endocytosis and are delivered into acidic endosomes, leading to release of viral genomic RNA into the cytoplasm by uncoating of the virion. Severe disease caused by WNV infection is manifested as neurological symptoms such as meningitis, encephalitis, and poliomyelitis. A nonpathogenic laboratory strain of WNV (Sarafend strain) binds to $\alpha_{\mathrm{V}} \beta_{3}$ integrin as a viral receptor and enters cells through a clathrin-dependent endocytic pathway and activation of focal adhesion kinase (FAK) $[56,57]$. However, NY385-99 strain of WNV utilizes a raft-mediated endocytic pathway that is not associated with $\alpha_{\mathrm{V}} \beta_{3}$ integrin and FAK activation [16]. Use of membrane rafts in the entry process depends on the virus strain.

DEN, an important arthropod-borne human pathogen, is clinically manifested from a simple self-limited febrile illness known as dengue fever to a hemorrhagic fever and potentially fatal hemorrhagic shock syndrome. Reported candidates of the DEN receptor for the entry process include dendritic cell-specific ICAM 3-grabbing nonintegrin (DCSIGN) [58], heparan sulfate [59], heat shock proteins (HSPs) [18], and neolactotetraosylceramide [60]. HSP90 and HSP70 are part of a receptor complex of DEN and are associated with membrane rafts essential for virus entry into neuroblastoma cells and human monocytes/macrophages [18, 19]. DC-SIGN is present in membrane rafts [61], and neolactotetraosylceramide is a sphingolipid within membrane rafts. One of risk factors of hemorrhagic fever and fatal hemorrhagic shock syndrome after secondary infection with a serotype different from the primary infection is probably antibody-dependent enhancement (ADE), which can be explained by the hypothesis that preexisting nonneutralizing antibodies will generate immune complexes with a new serotype secondary-infecting DEN, leading to enhancement of the capacity to infect macrophages and other $\mathrm{FC}_{\Upsilon}$ receptor$\left(\mathrm{FC}_{\mathrm{Y}^{-}}\right)$bearing cells. The ADE of DEN-4 infection in the human myelomonocyte cell line U937 has been suggested to require membrane rafts [20]. The entry process of JEV, the leading cause of acute encephalitis in South-East Asia, also requires membrane rafts in neural stem/progenitor cells $[19,21]$, possibly via the putative receptor HSP70 [62] and heparin sulfate [63] like DEN. The phosphatidylinositol-3 kinase (PI3K)/Akt pathway is activated through membrane rafts as a signal platform during early JEV infection, resulting in increased production of the infectious progeny viruses [21].

HCV is a major cause of chronic liver disease, including chronic hepatitis, hepatic steatosis, cirrhosis, and hepatocellular carcinoma. A cholesterol-removing reagent has an inhibitory effect on HCV entry through the virus receptor CD81 within membrane rafts [22]. Sphingomyelin hydrolysis shows a strong inhibitory effect on HCV entry, because ceramide enrichment of the plasma membrane leads to a decreased level of CD81 at the cell surface membrane by enhancement of CD81 internalization [23]. Thus, the entry process of HCV through CD81 is partially dependent on some major raft components, such as cholesterol and sphingomyelin, at the cell surface membrane.

EBV is a human herpesvirus causing infectious mononucleosis and is associated with a variety of human lymphocytic and epithelial neoplasms, including Burkitt's lymphoma and nasopharyngeal carcinoma. EBV can recognize human complement receptor type 2 (CR2), also known as CD21, on the cell surface membrane of B lymphocytes [24, 64]. Complexes of CD21 with CD19 and palmitoylated CD81 are present in membrane rafts. CD19/CD21/CD81 complexes in part stabilize B-cell antigen receptor (BCR) within membrane rafts, thus leading to enhancement of BCR-mediated signaling [25].

HSV, belonging to the family of alphaherpesvirus, is a pathogen causing mucosal lesions of the mouth and genital organs in humans. HSV binds to and enters host cells through complicated processes involving the essential viral glycoproteins $\mathrm{B}(\mathrm{gB}), \mathrm{gD}, \mathrm{gH}$, and $\mathrm{gL}$ and multiple cellular molecules including the tumor necrosis factor receptor (TNFR) family [65], nectin-1 or nectin-2 (two members of the immunoglobulin superfamily) [66], paired immunoglobulin-like type 2 receptor (PILR) [67], and a particular type of modified HSPGs $[68,69]$. The association of TNFR with membrane rafts is essential for tumor necrosis factor alpha$(\mathrm{TNF} \alpha-)$ mediated nuclear factor-kappaB $(\mathrm{NF}-\kappa \mathrm{B})$ activation [70]. Similarly, the association of HSPG with membrane rafts is correlated with protein kinase $\mathrm{C}$ alpha $(\mathrm{PKC} \alpha)$ activation [71]. Nectin-1 binding to gD of HSV-1 is not associated with membrane rafts either before or during HSV-1 infection in several cell lines. In the absence of $\alpha_{\mathrm{V}} \beta_{3}$-integrin, HSV-1 utilizes raft-independent and dynamin2-independent pathways to reach the intracellular neutral $\mathrm{pH}$ compartment, where the viral envelope fuses with the plasma membrane [27]. The gB, but not $\mathrm{gC}, \mathrm{gD}$, or $\mathrm{gH}$, of HSV-1 is associated with membrane rafts after virus attachment and during virus entry. Moreover, a cholesterol-removing reagent results in inhibition of HSV-1 and pseudorabies virus entry [26, 28]. These findings indicate that $\mathrm{gB}$ may interact with a cellular molecule within membrane rafts that may serve as a platform for HSV-1 entry and cell signaling. Also, $\alpha_{\mathrm{V}} \beta_{3}$-integrin expression on nectin-1-positive cells allows HSV-1 to enter cells 
through a raft-dependent and dynamin2-dependent pathway and reach the intracellular acidic compartment, where the viral envelope fuses with the plasma membrane. The pathway dictated by $\alpha_{V} \beta_{3}$-integrin utilizes membrane rafts, the platforms for a number of Toll-like receptors, suggesting that $\alpha_{\mathrm{V}} \beta_{3}$-integrin functions as a sentinel of innate immunity [27].

HHV-6, a betaherpesvirus related to human herpesvirus 7 and human cytomegalovirus, is a human pathogen of emerging clinical significance. Human CD46, a cellular receptor for HHV-6, is not associated with membrane rafts in uninfected cells. However, after virus attachment, CD46 is localized to membrane rafts. When membrane rafts are disrupted by a cholesterol-removing reagent or rescued by addition of exogenous cholesterol, the entry process of HHV-6 is inhibited or partially recovered, respectively. Membrane rafts appear to play an important role in the HHV-6 entry process as an entry site on the host cell surface [29].

HHV-8, the most recently identified member of human gammaherpesviruses, is consistently identified in all forms of Kaposi's sarcoma, primary effusion lymphoma, and multicentric Castleman's disease. Reduced HHV-8 infection and decreased cellular signals associated with the virus infection by raft disruption suggest that membrane rafts in microvascular dermal endothelial cells are required for HHV-8 infection and gene expression, due to their potential roles in the modulation of HHV-8-induced PI3K, RhoA-GTPase, and Diaphanous-2 (a RhoA-GTPase-activated adaptor molecule involved in microtubule activation) signal molecules, which play roles in virus entry processes after receptor binding [30]. Although activation of these signals involved in actin dynamics plays an important role in the entry process and endosomal sorting of HHV-8, the virus enters cells mainly through a clathrin-dependent pathway, but not a raft-dependent pathway, in endothelial cells [31].

Influenza viruses, highly transmittable pathogens of severe acute respiratory symptoms in various animals including humans, avians, and swines, enter host cells through multiple pathways including clathrin-independent endocytosis, caveola-independent endocytosis, and macropinocytosis depending on the cell type [33, 35-37] after binding of a viral envelope glycoprotein, hemagglutinin (HA), to glycoconjugates containing sialic acid on the cell surface [72, 73]. The viruses carried to late endosomes acquire fusion activity of HA given by its low-pH-dependent conformation change, leading to membrane fusion between the virus and endosomes. The viral ribonucleoprotein (RNP) complexes including the viral RNA genome are then released to the cytoplasm of host cells by proton influx of viral ion channel M2 protein that requires binding with cholesterol $[32,74]$. HA concentration to membrane rafts provides a sufficient amount of HA for the progeny virus envelope so that it can express efficient fusion activity for cellular membranes [34]. Influenza virus and capsid-like core particles of hepatitis B virus (Hepadnaviridae) can also internalize through clathrindependent endocytosis alone without the use of membrane rafts [75].

Vaccinia virus had been established as a vaccine that eradicated smallpox disease. Immediately after virus infection, the viral envelope proteins A14, A17L, and D8L, but not $\mathrm{H} 3 \mathrm{~L}$, are present in membrane rafts on the cell surface. Initial attachment of the virus to viral receptor glycosaminoglycans is not required for such membrane raft formation. On the other hand, cholesterol-containing membrane raft formation with these viral envelope proteins is observed when vaccinia virus penetrates into a wide variety of mammalian cells from different hosts [38].

HIV-1, a pathogen causing long-term and chronic disease that gradually progresses to acquired immunodeficiency syndrome, binds to viral receptor CD4 on the cell surface by the viral envelope glycoprotein gp120. Conformational change of gp120 after receptor binding leads to interaction with viral coreceptors, chemokine receptor CXCR4 or CCR5, and a subsequent conformational change of the viral envelope glycoprotein gp41 that confers membrane fusion activity [7678]. Approximately $11-18 \%$ of CCR5 in human adenocarcinoma cells, 90-95\% of CD4 in H9 leukemic T cells, and 50$66 \%$ of CD4 in peripheral blood mononuclear cells (PBMCs) are detected in membrane rafts $[79,80]$, whereas CXCR4 is almost entirely absent in membrane rafts of human embryonic kidney 293T cells, H9 leukemic T cells and PBMCs $[39,80]$. However, recent research indicates that the viral clustering of coreceptor CXCR4 in membrane rafts on 293T cells (not human glioma NP2 and human rhabdosarcoma TE671), rather than that of the viral receptor CD4, is the key step for the entry process of HIV-1 [44]. Interactions between CD4 and CCR5, which occur outside membrane rafts, have been postulated to influence susceptibility to the entry process of CCR5-tropic HIV [81]. A recent study has demonstrated that CD4 and CCR5 in macrophages are partitioned to membrane rafts and has suggested that macrophage membrane cholesterol is required for the entry process of HIV, implicating involvement of membrane rafts [43]. Additionally, glycosphingolipids abundantly present in membrane rafts of host cells, such as Gb3Cer, GM3 gaglioside, and galactosylceramide, have been shown to be involved in the interaction with viral glycoproteins and in the virus entry process $[45,82-85]$. The presence of Gb3Cer within membrane rafts in glomerular cells, but not tubular cells, may play a role in HIV nephropathy through binding of gp120 [86]. However, HIV-1 entry into primary human brain microvascular endothelial cells appears to be a raft-independent mechanism associated with proteoglycans such as cellassociated heparin sulfate and chondroitin sulfate [87].

HTLV-1, an oncogenic pathogen causing human adult T cell leukemia, enters host cells through glucose transporter 1 (GLUT-1) [88] that is targeted to membrane rafts for glucose deprivation [89]. Inhibition of vial entry and syncytium formation of the infected cells by a cholesterol-removing reagent suggests the involvement of membrane rafts in the entry and fusion processes of HTLV-1 [46, 47].

Alphaviruses such as Semliki Forest virus and Sindbis virus, arthropod-borne pathogens of infectious arthritis and rashes being the most commonly observed, require cholesterol for the virus entry process and especially for the membrane fusion process between the virus and the endosome triggered by low $\mathrm{pH}$ of acidic endosomes [48, 49, 52]. Direct binding of E1 fusion protein of Semliki Forest 
virus to cholesterol promotes viral fusion and infection in a cholesterol-dependent manner, unlike flaviviruses such as DEN and yellow fever virus, which show no significant binding of viral fusion proteins to cholesterol [90]. However, alphaviruses may not require membrane rafts for cholesteroldependent promotion of fusion with target membrane [51]. Similarly, the entry process of lymphocytic choriomeningitis virus (LCMV; Arenaviridae) is also known to be raft independent but to require membrane cholesterol [4]. Cholesterol dependence may not necessarily be linked to the function of membrane rafts for the virus entry process.

\section{Entry of Nonenveloped Viruses}

Entry processes of nonenveloped viruses associated with membrane rafts have been investigated for species $C$ human adenovirus (HAdV; Adenoviridae) [91, 92], Coxsackie virus A9, B3, and B4 (Picornaviridae) [93-96], echovirus types 1 and 11 (Picornaviridae) [97-102], enterovirus (Picornaviridae) [98], Rhinovirus (Picornaviridae) [103], BK virus ( $\mathrm{Pa}-$ povaviridae) [104-106], bovine papillomavirus (Papovaviridae) [107], human papillomavirus (HPV; Papovaviridae) [108-116], JC virus (Papovaviridae) [117], simian virus 40 (SV40; Papovaviridae) [118-126], bluetongue virus (Reoviridae) [127], and Rotavirus (Reoviridae) [128-130].

$\mathrm{HAdV}$, a common pathogen of acute respiratory disease and epidemic keratoconjunctivitis, is frequently used as viral vectors for gene therapy, most of which are serotype 5 that generally utilize a clathrin-dependent endocytic pathway. Initial interaction of HAdV with the cellular coxsackievirus and adenovirus receptor (CAR) and heparin sulfate glycosaminoglycans [131] is followed by interaction of the RGD motif of the virus with $\alpha_{\mathrm{V}} \beta_{3}, \alpha_{\mathrm{V}} \beta_{5}, \alpha_{\mathrm{M}} \beta_{2}$, and $\alpha_{5} \beta_{1}$ integrins, resulting in clathrin-dependent entry of HAdV into hematopoietic cells. In contrast, mature B-cell plasmocytes and Chinese hamster ovary (CHO) cells, which are CAR-negative cell lines, are permissive to HAdV2, HAdV4, and HAdV5, probably through a clathrin-independent and cave$\mathrm{ola} / \mathrm{raft}$-dependent endocytic pathway $[91,92]$.

Coxsackievirus A9 infection is one of the most frequent causes of aseptic meningitis and causes various symptoms such as flaccid paralysis, respiratory disease, and chronic myocarditis. This virus utilizes $\alpha_{\mathrm{V}} \beta_{3}$ integrin as a viral receptor, glucose-regulated protein 78 (GRP78) as a viral coreceptor, and accessory molecule major histocompatibility complex class I (MHC-I) for the entry process. Receptor molecules $\alpha_{\mathrm{V}} \beta_{3}$ integrin and GRP78 as well as MHC-I are concentrated as a virus entry site in membrane rafts following virus infection. The relationship between activation of Raf/mitogen-activated protein kinase (MAPK) within rafts during infection and virus entry is unclear [93, 94]. Coxsackievirus B4 is a human pathogen causing insulin-dependent diabetes mellitus, also known as type I diabetes, by progressive destruction of pancreatic $\beta$ cells. Attachment of this virus to viral receptor molecules, CAR and CD55, seems to induce the recruitment of these molecules into membrane rafts. Internalization of Coxsackievirus B4 rapidly to the Golgi apparatus is independent of clathrin and appears to be dependent on membrane rafts. However, it has been suggested that CAR can also follow the clathrin-mediated pathway [95]. Coxsackievirus B3 is a human pathogen causing febrile illness, meningitis, and myocarditis. Coxsackievirus B3 Nancy strain cannot bind to the glycosylphosphatidylinositol-(GPI-) anchored complement regulatory protein decay-accelerating factor (DAF), but RD strain, a DAFbinding derivative of Nancy strain, can. Coxsackievirus B3 RD strain possessing the ability of DAF binding enters polarized human intestinal Coca-2 cells through a caveola-dependent but dynamin-independent pathway that requires DAFmediated tyrosine kinase signals, whereas entry of this strain into nonpolarized HeLa CCL-2 cells requires dynamin and membrane rafts with CAR but not clathrin or caveolin, indicating that the entry pathway of this virus is dependent on cell type such as polarized and nonpolarized cell lines and that the requirement of membrane rafts differs significantly from that of caveolin for virus entry. Coxsackievirus B3 Nancy strain possessing no ability of DAF binding utilizes an entry mechanism similar to that of the RD strain in HeLa CCL2 cells, suggesting no influence of DAF binding on virus entry into HeLa CCL2 cells [96].

Echovirus type 1 and a number of enteroviruses including echovirus type 11 cause nerve paralysis, cerebral meningitis, respiratory symptoms, and anathema. These viruses utilize $\alpha_{2} \beta_{1}$ integrin and DAF on the cell surface as the respective receptors, which induce caveola-dependent and membrane raft-dependent endocytosis [97-101]. However, a recent study has suggested that binding of clustered $\alpha_{2} \beta_{1}$ integrin with echovirus type 1 initiates a unique entry pathway that is p21-activated kinase 1 (Pak1), GTP-binding protein Rac1, PI3K, phospholipase C (PLC) and actin-dependent but clathirin and caveolaindependent and that can sort cargo to caveosomes [102].

Rhinoviruses, general pathogens of cold and acute respiratory symptoms, colocalize with ceramide-enriched membrane platforms during infection. Rhinoviruses induce microtubule- and microfilament-mediated translocation of acid sphingomyelinase from an intracellular compartment onto the extracellular leaflet of the cell membrane. The enzymatic activity of acid sphingomyelinase hydrolyzes sphingomyelin to ceramide in the cell membrane, finally leading to the formation of large ceramide-enriched membrane platforms. Genetic and pharmacological prevention of acid sphingomyelinase has shown the involvement of ceramide-enriched membrane platforms in Rhinovirus entry [103]. Although previous studies have shown the existence of many receptors for Rhinovirus entry, ninety percent of human Rhinovirus immunogenic variants use intercellular adhesion molecule-1 (ICAM-1) as a receptor [132-134], which is known to be a component of ganglioside GM1-containing membrane rafts [135].

HPVs are well-established pathogens causing cervical cancer and have also been implicated as pathogens in other epithelial cancers, including head and neck cancers. Over 100 different types of HPV, including types 16, 18, 31, 33, 35, 39, $45,51,52,56,58,59,66$, and 68 as high-risk carcinogenic HPVs and types $6,11,32,34,40,42,43,44,53,54,55,61$, 70, 72, 73, 81, 83, 84, 89, and Pap155 as low-risk HPVs, have been identified. In most cases, type 16 is the primary 
etiologic agent for anogenital malignancies, particularly cervical cancer [136]. Increased expression of HPV type 18 by addition of cholesterol suggests involvement of the HPV infection cycle in membrane rafts [109]. The entry process of HPV begins with viral binding to specifically modified heparan sulfate proteoglycans (HPSGs), most likely syndecans. In addition, $\alpha 6$ integrin and laminin 5 have been suggested to be transient receptors for HPV. Although association of HSPGs with membrane rafts has been shown [71], binding of HPV type 33 pseudovirus to HSPGs is followed by delayed caveola-independent endocytosis [110]. Interestingly, the entry process of HPV types 16 and 58 involves clathrin-dependent endocytosis, whereas that of HPV type 31 involves caveola-dependent endocytosis, indicating that HPVs use distinct routes for entry into COS-7 cells (a monkey kidney cell line) [111]. In human keratinocytes (a natural host cell type of HPVs), remarkably slow entry and initiation of HPV type 31 early infection require both caveolin-1 and dynamin-2 (entry half-time of approximately $14 \mathrm{~h}$ ), different from fast clathrin-dependent endocytosis of HPV type 16 (entry half-time of $4 \mathrm{~h}$ ) [114]. Both HPV types 16 and 31 require the acidic compartment of the endosomal pathway, where low $\mathrm{pH}$ induces a conformational change in the HPV capsid to promote viral genome uncoating. Binding of and infection with HPV type 16, but not HPV type 31, require HPSGs in human keratinocytes. The different mechanisms of these two HPV types may reflect the distinct binding requirement [115]. However, in COS-7 cells, and 293TT cells (a simian virus 40 large $\mathrm{T}$ antigen-transformed human kidney cell line), HPV type 31, like HPV type 16, enters the cells through a clathrin-dependent pathway rather than a caveola-dependent pathway as described above [113]. HPV type 16 also uses a novel endocytic pathway associated with tetraspanins CD63 and CD151 in HeLa cells, independently of clathrin and caveolin [116]. Complexes of tetraspanins CD63 and CD151 with $\alpha 6$ integrin and laminin through $\beta 4$ palmitoylation of these tetraspanins induce assembly of cholesterol-associated microdomains that are distinct from membrane rafts $[137,138]$. These tetraspanin-enriched microdomains may serve as an entry platform of HPV type 16. The different entry routes for HPV types 16 and 31 might result from different host cell types, such as human keratinocytes, COS-7 cells and 293TT cells, and from dependency of HPV lifecycles on cell differentiation. Although the involvement of distinct endocytic pathways in HPV typedependent pathogenicity remains unclear, results obtained from human keratinocytes, a natural host cell line of HPVs, may be close to the truth of the entry process. BK virus, a pathogen of an infectious complication termed polyomavirus-associated nephropathy in renal transplant recipients, enters Vero cells and human renal proximal tubular epithelial cells by a slow caveola-dependent and clathrinindependent pathway in a pH-dependent manner [104106]. JC virus and bovine papillomavirus enter cells through clathrin-dependent endocytosis and are subsequently transported from early endosomes to caveolar vesicles and then carried by a slow caveola-dependent pathway $[107,117]$.

Caveola-dependent endocytosis has been studied mostly by analysis of cell entry of polyomaviruses represented by of
SV40, which causes cancer in some animals through repression of tumor suppressor p53 [139]. After SV40 attaches to MHC-I on the cell surface, caveola and caveolin-1 are recruited to the association site of SV40 [140, 141]. Then virusincorporated caveola undergoes budding from the cellular membrane after activation of tyrosine kinases, actin skeleton depolymerization, actin tail formation, and dynamin accumulation around the association site [121, 123]. Finaly, caveola carries the virus to the endoplasmic reticulum (ER) along cellular microtubules. SV40 receptor MHC-I is not localized in membrane rafts, but attachment induces association of the virus with caveola [118-122] or ganglioside GM1 that is enriched in membrane rafts as a viral receptor $[124,125]$. As for other polyomaviruses, BK virus and JC virus, but not mouse polyomavirus, have been reported to use caveoladependent endocytosis for the entry process [104-106, 117, 142]. Bluetongue virus-1 can infect baby hamster kidney (BHK) cells through an entry process that is clathrin dependent and cholesterol dependent but requires dynamin [127].

Rotaviruses, pathogens of severe diarrhea in infants and young children, recognize several molecules on the epithelial cell surface, including glycolipids, $N$-glycoproteins, HSC70 protein, and $\alpha_{\mathrm{V}} \beta_{3}$ integrin localized in membrane rafts [128, 129].

\section{Role of Membrane Rafts in Virus Genome Replication, Assembly, and Budding}

Evaluation of the role of membrane rafts in viral assembly and budding has been performed by examining the inhibitory effect of progeny virus formation and production when membrane rafts are disrupted by a cholesterol-removing reagent or a cholesterol synthesis inhibitor. In cholesterol-depleted infected cells, impaired virus formations and productions are recovered by the addition of exogenous cholesterol. General biochemical methods have also been used to determine whether several viral structural proteins during the process of virus formation and assembly are colocalized with the detergent-insoluble fraction or a representative raft-marker such as caveolin-1, flotillin, or GM1. Raftdependent virus budding and replication have also been evaluated by examining the inhibitory effect of caveola formation using an RNAi method and dominant-negative protein expression for normal caveolin-1 knockdown. If the raftassociation sites have been identified in the viral structural proteins, it is possible to generate mutated viral proteins that do not associate with membrane rafts. Then evaluation of virus assembly and budding in membrane rafts can also be performed by measuring intracellular transport or incorporation rate of these mutated proteins into virus particles or characterization of viruses possessing these mutated proteins generated by established reverse genetics methods. When virus budding of enveloped viruses occurs in membrane rafts, colocalization of the budded virus and a raft marker on the cell surface membrane can be observed by using an electronic microscope. 


\section{Genome Replication, Assembly, and Budding of Enveloped Viruses}

The role of membrane rafts in viral RNA synthesis of enveloped viruses has been investigated for hepatitis $C$ virus (HCV; Flaviviridae) [86, 143-147], DEN [148, 149], JEV [148], and respiratory syncytial virus (RSV; Paramyxoviridae) $[150,151]$.

Association of HCV nonstructural (NS) proteins with cholesterol-enriched membrane rafts in the Golgi-derived membrane results in the formation of the replication complexes (distinct particle structures of about $0.7 \mu \mathrm{m}$ in size) for HCV RNA synthesis [86, 143, 144]. A lipophilic longchain base compound, NA255, has been identified as a smallmolecule HCV replication inhibitor from a secondary fungal metabolite. NA255 disrupts the association of HCV NS proteins with membrane rafts by prevention of the de novo synthesis of sphingolipids, major membrane raft components [145]. The sphingomyelin-binding domain of HCV RNAdependent RNA polymerase is the membrane raft localization domain of viral nonstructural protein NS5B [146]. Since cholesterol-depleted or sphingomyelin-hydrolyzed virus has a defect in cellular internalization but not cell attachment, incorporation of cholesterol and sphingolipid into $\mathrm{HCV}$ particles also plays an important role in virus maturation and infectivity. Although newly synthesized structural proteins of HCV localize into membrane rafts on the cellular membrane of infected cells, it is unclear whether these membrane rafts are derived from lipids on the viral particles or not. Alternatively, membrane rafts may serve as a budding site of HCV in the ER [147].

On the cell surface and in the viral RNA replication complexes, membrane rafts are associated with the NS1 of all four DEN serotypes and JEV. Efficient viral RNA replication of flaviviruses requires NS1, which can be found in the cell as a monomer associated with cellular organelle membranes and colocalized with the viral replication complex and as a dimer in a membrane GPI-anchored form colocalized with membrane rafts, and it is also secreted as a hexamer from infected cells [148, 149].

Human RSV is a major pathogen of severe lower respiratory tract disease in infants, children, immunosuppressed individuals, and the elderly. The viral proteins, nucleoprotein $(\mathrm{N})$, phosphoprotein $(\mathrm{P})$, large polymerase subunit (L), matrix protein (M) and $\mathrm{M} 2-1$, are located in membrane rafts in virus-infected cells. Viral RNP complexes are formed by interactions of viral genomic RNA with $\mathrm{N}, \mathrm{P}, \mathrm{L}$, and M21 proteins. The association of viral RNP complexes with membrane rafts leads to efficient RNA polymerase activity that may require interaction with cellular factor HSP70 (one of the viral receptor candidates) in a raft-dependent and ATP-dependent manner [150, 151].

The role of membrane rafts in the assembly and budding of enveloped viruses has been investigated in Ebola virus [12, 152], Marburg virus [12], WNV [153], murine cytomegalovirus (MCMV; Herpesviridae) [154], HSV [155, 156], HHV-6 [157], influenza virus [34, 40, 158-171], measles virus (Paramyxoviridae) [40, 172, 173], Newcastle disease virus (NDV; Paramyxoviridae) [174, 175], RSV [150, 151,
176-179], Sendai virus (Paramyxoviridae) [180, 181], HIV-1 [40, 182-201], HTLV-1 [202], and vesicular stomatitis virus (VSV; Rhabdoviridae) [203, 204].

Ebola virus and Marburg virus use membrane rafts bearing viral glycoproteins as a platform for budding from host cells, in addition to entry. Hence, released virus particles incorporate the raft-associated molecule GM1 but not transferrin receptor, a protein absent from membrane rafts [12]. The matrix protein VP40 of Ebola virus, which plays an essential role in virus assembly and budding, oligomerizes in membrane rafts. The cellular TSG101 protein, a component of the vacuolar protein sorting machinery, actively targets along with VP40 to membrane rafts at the cell surface, by binding of VP40 with a PTAP motif of TSG101. Thus, budding complexes containing VP40 and TSG101 accumulate in membrane rafts to promote virus budding [152].

WNV spreads from the blood stream to the central nervous system and peripheral tissues across endothelial cells. Virus-like particles of highly virulent WNV NY99 6-LP strain are transported from the apical side to basolateral side of endothelial cells as the virus budding site in a raft-dependent manner, whereas those of low-virulent WNV Eg101 strain are hardly transported. Membrane rafts may be involved in a transport pathway for basolateral destinations of WNV within endothelial cells [153].

MCMV (belonging to the betaherpesvirus UL78 family) M78 protein, a 7-transmembrane receptor homologue, traffics to the surface membrane of infected cells, but is rapidly and constitutively internalized through both clathrin-dependent and caveola/raft-dependent pathways. Such an M78 subcellular localization may contribute to the incorporation of M78 into the viral envelope during virus maturation [154].

Six envelope glycoproteins, gH, gL, gQ1, gQ2, g, and gB, of HHV-6 are present in membrane rafts during the course of virus maturation. GM1, a representative raft marker, is incorporated into mature virus particles along with these viral envelope glycoproteins, indicating that HHV-6 may assemble through membrane rafts [157].

The HSV tegument contains the less-abundant virus particle host shutoff (vhs) protein encoded by the HSV late gene UL41, which enhances the turnover of all kinetics of viral mRNA and is likely to be important in the increased removal of immediate-early and early viral transcripts to facilitate the switch to late gene expression. Only a small proportion of total cellular vhs proteins are associated with membrane rafts. Nevertheless, a large proportion of the vhs proteins exist in HSV-containing cytoplasmic organelles, indicating that membrane rafts may correlate with assembly of vhs protein into the tegument [155]. The UL11 and UL51 gene products of HSV are membrane-associated tegument proteins that are incorporated into the HSV envelope during virus maturation. HSV UL11 is associated with cholesteroland glycosphingolipid-enriched membrane rafts through its posttranslational myristoylation and palmitoylation into the Golgi apparatus, but UL51, which is only palmitoylated, has no association with the membrane rafts. UL11 and UL51 appear to function at different steps in progeny virus 
maturation [156]. Involvement of membrane rafts in HSV assembly and budding remains to be clarified.

Influenza virus particles consist of vial RNP with two spike envelope glycoproteins, HA and neuraminidase (NA), and ion channel M2 protein on the outer surface and internal M1 protein and nonstructural NS2 protein on the inner surface. Membrane rafts are associated with the transmembrane domains and cytoplasmic tails of HA [162] and NA [162, 163 ] and with the short transmembrane domains of M2 [74, 169, 205] and NP [164], but not M1. These domains of HA and M2 contain palmitoylated cysteine residues that are required for hydrophobic interactions with lipids and cholesterol of membrane rafts. M2 also possesses a putative cholesterol recognition/interaction amino acid consensus (CRAC) motif in addition to palmitoylation of its amphiphilic helix. The targeting to membrane rafts of M2 requires the palmitoylation but not the CRAC motif [171]. Although the transmembrane domains and the cytoplasmic tails of NA are essential for the association with rafts, there is no evidence that NA contains palmitoylated cysteine residues. The mechanism by which NP associates with rafts remains unknown. HA, NA, NP, and M2 independently use membrane rafts together with each apical targeting signal sequence for the apical sorting process, leading to efficient preferential budding and release of progeny viruses from the apical surface membrane. However, membrane rafts are not necessarily required for apical sorting of these viral proteins, indicating that apical sorting machineries of these viral proteins also exist outside their membrane rafts [158, 160162, 164]. For example, cellular protein VIP17/MAL, a raftassociated protein, is involved in apical transport of HA in dog kidney MDCK cells [206]. M1, a non-raft protein, is incorporated into membrane rafts through its interactions with cytoplasmic tails of both HA and M2, which facilitate the recruitment of internal viral proteins and viral RNP to the cell surface membrane for efficient virus assembly and budding $[162,207]$. Although M1 has been believed to play a critical role in viral assembly and budding $[208,209]$, recent studies have indicated that HA, NA, and M2, but not M1, are required for assembly and budding of influenza virus particles $[167,169]$.

GM-95 cells are mutant cells of mouse B16 melanoma that cannot synthesize major glycosphingolipids including gangliosides due to lack of ceramide glycosyltransferase gene, the first enzyme of glucosylceramide series synthesis. GM95 cells can be infected by influenza A viruses and produce infectious progeny viruses, regardless of the absence of major glycosphingolipids [73]. Since gangliosides are major components of rafts and viral receptors, it has been suggested that they are not absolutely necessary for the influenza virus lifecycle. This suggestion for virus assembly and budding is supported by evidence that infectious progeny viruses can be produced from cells infected with mutant viruses possessing HA and NA that lack the ability to interact with membrane rafts by mutations of their raft-binding domains [34, 163] and that membrane raft disruption enhances virus budding from MDCK cells [168]. How membrane rafts help the influenza virus lifecycle needs to be addressed in future studies. The concentration and clustering of HA and NA in the same membrane rafts facilitate efficient incorporation of these raft-associated viral proteins into the progeny viral membrane during the budding process $[34,163]$, because progeny virus particles are selectively budded together with membrane rafts from the cell surface [159]. At that time, M2 is distributed in a different type of membrane rafts from those associated with HA and NA or is located in non-raft compartments on the cell surface, resulting in poor incorporation into the progeny viral membrane [165]. On the other hand, a study has shown that M2 interacts with membrane rafts associated with HA dependent on an intact actin cytoskeleton and thereby M2 targets to the raft lipid-enriched zone, the viral budding site on the cell surface membrane, organized by HA [170]. Disruption of membrane rafts results in decreased infectious progeny virus production concomitantly with enhancement of the release total infectious and noninfectious virus particles from infected cells [168]. Taken together, the results of studies indicate that the role of membrane rafts in the influenza virus lifecycle is contribution to an efficient incorporation of raft-associated viral proteins into the progeny viral membrane and pinchingoff of virus particles from the plasma membrane.

In infected cells, the tight association of newly synthesized HA transferred to the cell surface with membrane rafts stimulates cellular Raf/MEK/ERK signaling of the MAPK pathway through $\mathrm{PKC} \alpha$ activation. MPAK activation induces nuclear export of viral RNP compexes from the nucleus to the cytoplasm, leading to enhanced production of infectious progeny viruses [166]. Our recent study has shown that sulfatide, 3-O-sulfated galactosylceramide, is required for efficient virus replication and that association of newly synthesized HA transferred to the infected cell surface with sulfatide induces nuclear export of viral RNP complexes from the nucleus to the cytoplasm, leading to enhanced production of infectious progeny viruses [210]. Thus, association of HA with sulfatide may trigger MAPK activation that enhances nuclear export of viral RNP complexes. Some studies have shown that existence of sulfatide associated with membrane rafts $[211,212]$, but lipid composition in the purified influenza virus envelope propagated in embryonated eggs does not contain any acidic glycosphingolipids including sulfatide [162]. Further investigation is needed to determine whether enhanced nuclear export of viral RNP is triggered by raft-associated or non-raft sulfatide.

Measles virus is a pathogen of an acute respiratory disease and causes the death of over one million children each year, principally because of virus-induced immunosuppression of lymphocyte function. Membrane rafts act as a platform of the virus assembly process but not the budding process. The transmembrane domain of the viral surface fusion (F) protein has two palmitoylated cysteines, which probably interact with membrane rafts [213]. The $\mathrm{F}$ protein is synthesized as an inactive precursor $\left(\mathrm{F}_{0}\right)$ that is proteolytically cleaved in the trans-Golgi network and thereby converted to the biologically active form, disulfide-linked subunits $\mathrm{F}_{1}$ and $\mathrm{F}_{2}$. After transport of two mature viral envelope glycoproteins, hemagglutinin $(\mathrm{H})$ and $\mathrm{F}$ proteins, to the trans-Golgi network, they are preferentially incorporated into membrane rafts, but the $\mathrm{F}_{0}$ precursor is not. Internal structural proteins, 
$\mathrm{M}$ and $\mathrm{N}$, interact with membrane rafts possibly through acylation of saturated chains, regardless of the presence of the two viral envelope glycoproteins. The nonstructural $\mathrm{V}$ protein remains excluded from rafts during the course of virus infection. Although the $\mathrm{M}$ protein can interact with the cytoplasmic tail of the F protein in $\mathrm{H}-\mathrm{F}$ complexes, it can also bind to plasma membranes and the $\mathrm{N}$ protein, thereafter in turn binding to the viral internal structural proteins, $\mathrm{P}$ and L. Eventually, M-RNP complexes (composed of viral internal proteins $\mathrm{N}, \mathrm{P}$, and $\mathrm{L}$ with viral RNA) interact with the surface membrane through the $\mathrm{M}$ protein associated with membrane rafts and with $\mathrm{H}-\mathrm{F}$ complexes associated with membrane rafts through the F protein, resulting in efficient assembly of measles virus prior to the budding process $[172,173]$.

NDV is a highly contagious pathogen of zoonotic bird disease affecting many domestic and wild avian species. The assembly and budding of infectious progeny viruses preferentially occur in membrane rafts that interact with the cortical cytoskeleton [174]. Furthermore, intact membrane raft domains in the infected cells, but not in the virus envelopes, facilitate the proper formation or maintenance of the viral surface hemagglutinin-neuraminidase (HN) and F glycoprotein complexes (required for virus-cell membrane fusion) and the incorporation of the HN-F complexes into the viral surface, leading to the initiation of membrane fusion between the virus and cell [175].

Human RSV is a major cause of severe lower respiratory tract disease in young children, the elderly, and immunosuppressed adults. The viral envelope attachment G protein and the internal $\mathrm{M}$ and $\mathrm{N}$ proteins of RSV are present in membrane rafts. Caveolin, a raft marker, is present in the RSV envelope. RSV infection induces cellular distribution of phosphocaveolin-1 that is enriched at sites of attachment of the actin cytoskeleton. Therefore, RSV assembly at the plasma membrane is shown to occur in specialized membrane rafts that contain a high content of caveolin [176, 177]. The cytoplasmic tail of $\mathrm{F}$ protein plays an essential role in its cellular localization and production of infectious progeny viruses, dependently on interaction of $\mathrm{F}$ protein with membrane rafts [178]. Moreover, like the function of HIV1 Nef [192], RSV infection facilitates production of phosphatidylinositol 4,5-bisphosphate (PIP2) and phosphatidylinositol 3,4,5-triphosphate (PIP3) in the lipid composition of membrane rafts within virus inclusion bodies through lipid kinases containing PI3K. This change plays an important role in the assembly and budding processes of progeny virus [179].

Sendai virus, also known as murine parainfluenza virus type 1 , is a highly transmissible pathogen of respiratory tract infection in mice, hamsters, guinea pigs, rats, and occasionally pigs. The two viral envelope proteins, HN protein and $\mathrm{F}$ protein, interact with membrane rafts. The viral internal $\mathrm{M}$ protein appears to have no direct association with membrane rafts. When mature HN-F complexes specifically interact with $\mathrm{M}$ proteins through both the cytoplasmic tail and the transmembrane domain of $\mathrm{F}$ protein, the HN-F-M complexes are localized in membrane rafts, where the viral proteins have been suggested to be assembled [180]. However, further study led to the conclusion that the virus assembly complexes found in membrane rafts did not constitute a direct precursor of virus particle budding [181]. Two possible routes, raft dependent and raft independent, seem to be involved in Sendai virus assembly.

HIV-1 uses membrane rafts as a platform for viral assembly and budding $[182,188]$. Modification of the N-terminus of HIV-1 Gag protein with myristic acid is required for HIV1 assembly and budding [214]. Gag protein interacts with the plasma membrane through associations between its myristic acids and membrane rafts, leading to its incorporation into HIV-1 particles as an internal structural protein [188]. During the budding process, Gag-Gag interactions (Gag multimerization) occur through the N-terminus of the viral nucleocapsid (NC domain). Lower-ordered Gag multimerization, but not higher-order Gag multimerization, may enhance or stabilize Gag-membrane and Gag-raft interactions. Whether membrane rafts are responsible for increasing Gag-Gag interaction is unclear [186]. The viral envelope glycoprotein complexes (composed of gp120 and gp41) are incorporated into the HIV-1 envelope together with membrane rafts by interactions of Gag with the cytoplasmic tail of gp41, which stabilize the gp120-gp41 interactions. Palmitoylation in cytoplasmic tails of gp41 is required for interactions with rafts but not for interactions between gp41 and Gag protein. Moreover, although associations of rafts with both gp41 and Gag protein are not essential for HIV-1 assembly, infectious progeny virus production, and surface trafficking of the viral proteins $[185,189,190]$, the quantal interaction of Gag with cholesterol-enriched rafts facilitates HIV-1 particle production by enhancement of both Gag-membrane interaction and Gag multimerization [193, 194]. Interactions of Gag protein with Annexin 2 at the PIP2-enriched membrane rafts also increase virus production [196].

The Nef protein encoded by primate lentiviruses facilitates virus replication and thus increases the pathogenic potential of HIV. The myristoylated $\mathrm{N}$-terminus and its neighboring basic arginine and lysine residues of Nef increase viral transcription and HIV-1 infectivity through interactions with GM1- and cholesterol-enriched membrane rafts, where Nef binds to both the plasma membrane and the viral structural proteins and participates directly in formation of the budding scaffold, leading to incorporation of Nef into the virus particles, concomitantly with viral structural proteins $[183,184,187]$. The N-terminus of Nef determines its differential membrane avidity and its preferential incorporation into a specific membrane raft for surface membranes or for subcellular membranes [191], which Nef itself has the ability to regulate by modulating the lipid composition of the virus envelope and host cell membrane rafts through, for example, activation of lipid kinases such as PI3K [192]. HIV1 release from certain cell lines is enhanced by the viral Vpu protein, which is partitioned into membrane rafts. Transmembrane mutants of the Vpu protein have impaired HIV-1 particle release function due to deficiency of raft association but still maintain the ability to down regulate CD4 [200]. For HIV-1 assembly and budding, membrane rafts are also associated with cellular factors such as human cellular cystidine deaminase APOBEC3G (hA3G), BST-2/ CD317/HM1.24 (tetherin), caveolin-1, and tetraspanins. 
hA3G inhibits infectivity of progeny virus particles by its incorporation into virus particles through its association with membrane rafts $[195,201]$. Tetherin also exerts antiviral activity against HIV-1 and other enveloped viruses as an interferon-inducible factor of the innate immune system by inhibition of progeny virus particle release from the cell surface. Viral propagation among T cells proceeds by direct cellto-cell transmission through membrane raft-enriched synapses colocalized with tetherin, which counteracts the viral Vpu protein partitioned to membrane rafts, involved in virus release [199]. HIV-1 infection enhances the expression of caveolin-1, a major protein of membrane rafts. Although membrane rafts have been shown to contribute to assembly and budding processes of HIV-1, expression of caveolin-1 causes a reduction of virus production in macrophages [198]. This suggests that caveolin-1 may contribute to persistent infection in macrophages and that a caveolin-dependent raft, caveola, is not necessarily an advantage for the HIV-1 lifecycle. A tetraspanin-enriched microdomain is a unique type of protein-based microdomain, clearly distinct from membrane rafts. Tetraspanins CD9, raft-associated CD55, and raft marker GM1 are concentrated at the virus assembly site. This recruitment and confinement of CD9 are partially dependent on cholesterol, whereas those of CD55 are completely dependent on cholesterol. HIV-1 assembly creates specialized microdomains for recruiting components of both membrane rafts and tetraspanin-enriched microdomains [197]. As for retroviruses other than HIV, HTLV-1 assembly, but not budding and surface trafficking, is also inhibited by a decrease of Gag associations with membrane rafts by interferon $\alpha$-2a treatment [202].

VSV budding is known to occur at membrane microdomains containing the viral envelope $G$ glycoproteins, some of which are 100-150 $\mathrm{nm}$ in size and smaller than the virus envelope (approximately 100-150 nm) and others of which extended in size to a maximum of $300-400 \mathrm{~nm}$ from the tip of the virus budding site $[203,204]$. However, immunoelectron microscopy observation did not confirm that gold-labeled $\mathrm{G}$ protein-containing microdomains are equivalent to lipid-enriched membrane rafts. Furthermore, such microdomains of $300-400 \mathrm{~nm}$ in size are too large for the definition of raft microdomains of $10-200 \mathrm{~nm}$ in size [3]. A recent study has also shown that most $G$ proteins of wildtype VSV were not incorporated into membrane rafts in infected osteoclasts [215]. Relevance of membrane rafts on VSV infection will be settled in future studies.

\section{Genome Replication, Assembly, and Budding of Nonenveloped Viruses}

The role of membrane rafts in intracellular assembly of nonenveloped viruses has been investigated only in bluetongue virus [216] and Rotavirus [130, 217-220], belonging to the family Reoviridae. Association of SNARE (soluble N-ethylmaleimide-sensitive fusion attachment protein receptor) domain in the bluetongue virus outer capsid VP5 with membrane rafts may play an important role in its membrane targeting and virus assembly [216]. Rotavirus replication occurs at large inclusions (known as viroplasms) in the cell cytoplasm, which are sites for replication of viral RNA and assembly of double-layered particles. These particles are transferred across the ER membrane by interactions of the viral capsid protein VP6 with the nonstructural transmembrane glycoprotein NSP4, which has been characterized as an ER intracellular receptor and a viral enterotoxin for intestinal cells. During transfer across the ER, the virus acquires a transient lipid envelope that is finally lost and replaced by viral surface spike proteins, VP4 and VP7. In this process, the involvement of transient enveloped particles in membrane rafts is highly questionable since rafts are thought to be absent from the ER. Association of VP4 with membrane rafts in the extrareticular compartment facilitates rotavirus morphogenesis as a final assembly platform and apical targeting toward the release process $[130,217,218]$. The rafttype membrane microdomains associated with VP4 are significantly dependent on raft heterogeneity of cell lines [219]. Moreover, $N$-glycosylation of NSP4 is processed in the Golgi network through caveola-dependent Golgi networkbypassing transport [220].

\section{Role of Membrane Rafts in Virus-Induced Signal Transductions}

Viral replication efficiency, viral infection sites, and viral infectious diseases are frequently controlled by membrane rafts in host cells and immune cells. Membrane rafts also act as a scaffold of various cellular signal transductions. Involvement of membrane rafts in many viral infectious diseases often results from up- or downregulation of cellular signal transductions associated with cell proliferation, apoptosis, cell differentiation, immune response, and so on.

HTLV-1 Tax1 protein recruits I $\kappa$ B kinases (IKKs) to membrane rafts for persistent activation of NF- $\kappa$ B, which enhances T-cell proliferation, thereby contributing to HTLV1-induced T-cell leukemia [221].

Flaviviruses DEN type 2 and JEV activate the raft-dependent PI3K/Akt pathway that induces antiapoptosis in order to protect infected cells from early apoptotic cell death. However, this signaling is not essential for flavivirus replication. A balance between apoptotic and antiapoptotic signaling, which is triggered by the interplay between host and virus, controls the outcome of flavivirus infection [17]. DEN NS1, which can be found in membrane rafts on the host cell surface, increases NF- $\kappa$ B transcriptional activities by facilitating nuclear translocation of NF- $\kappa$ B p 65 protein in HepG2 cells, suggesting a possible contribution to DEN pathogenicity [149]. In JEV-infected microglia, the integrity of membrane rafts and the activation of Src-related Ras/Raf/ERK cascades participate in NF- $\kappa \mathrm{B}$ activation and consequent $\mathrm{TNF} \alpha$ and interleukin-1 beta (IL-1 $\beta$ ) expression. These signal activations and cytokine expressions caused by JEV infection may play a critical role in neuronal cell death [222].

The partitioning of measles virus $\mathrm{F}$ protein into high buoyant density-membrane rafts activates an alternative pathway of human complement independently of CD46 and $\mathrm{CD} 55$, which regulate the complement activation and do not exist in the same rafts as the F protein. Thus, measles 
virus infection induces inflammatory response through alternative complement activation [223]. Measles virus-induced immunosuppression also results from signal transduction alteration such as PI3K present in membrane rafts of T cells [224].

HSV-1 infection is implicated in Alzheimer's disease susceptibility by virus binding to HSPGs, nectin receptors, $\alpha 2$ macrolgobulin, blood-borne lipoproteins, and apolipoprotein E. Cholesterol reduction on the plasma membrane by a cholesterol synthesis inhibitor has been linked to a decrease in the risk for development of Alzheimer's dementia. Since HSV-1 uptake into cells is dependent on cholesterol and membrane rafts, cholesterol reduction may decrease the availability of raft-dependent pathways to spread HSV-1 in the brain $[225,226]$. Tyrosine kinase-interacting protein (Tip) of lymphotropic herpesvirus saimiri (HVS) downregulates T-cell receptor (TCR) and CD4 expression on the cell surface through its targeting to membrane rafts in T cells. Tip is required for cellular membrane deformation of $\mathrm{T}$ cells but not for viral replication, which induces lymphoma in primates [227]. HHV-8 encodes two RING finger E3 ubiquitin ligases (MIR1 and MIR2) that mediate ubiquitination and degradation of cellular proteins important for immune response. Many of the MIR substrates are believed to be present in membrane rafts. Function of MIR2 is required for its palmitoylation, which is known as a posttranslational modification that enhances recruitment of transmembrane proteins into membrane rafts. MIR2 function may play an important role in immune evasion of the virus and resultant persistent viral infection by MIR2-mediated downregulation of MHC-I and platelet endothelial cell adhesion molecule 1 (PECAM-1) [228].

GM1 expression and asialo-GM1 expression in membrane rafts of T cells and natural killer (NK) cells are differentially regulated by these cells in the context of RSV infection. Asialo-GM1 may increase RSV clearance by increasing IFN- $\gamma$ levels in mouse lungs [229].

The pseudorabies virus Us9 protein interacts with membrane rafts and then promotes targeting of viral structural proteins to neuronal axons. Consequently, the virus spreads from presynaptic to postsynaptic neurons and cells of the mammalian nervous systems [108].

Raft-dependent phagocytosis of HCV-infected apoptotic vesicles containing viral double-strand RNA (dsRNA) is required for maturation of human monocyte-derived dendritic cells (MoDCs). However, HCV JFH1 strain, which can efficiently replicate in cell culture, does not directly stimulate MoDCs for activation of T cells and NK cells [230]. HCV envelope E2 protein attenuates interleukin-2 (IL-2) production at the level of secretion by its interaction with tetraspanin CD81 coreceptor and sequent recruitment of protein kinase $\mathrm{C}$ beta $(\mathrm{PKC} \beta)$, which is essential for IL-2 secretion, to membrane rafts in peripheral blood mononuclear cells. The ability of the E2 protein to attenuate IL-2 and IFN- $\gamma$ secretion has been suggested to contribute to a mechanism for $\mathrm{HCV}$ to evade the human immune response and to establish persistent infection [231].

Antibodies against SARS-CoV spike domain2 (S2) in patient sera can cross-react with human lung epithelial cells through annexin A2, which has been identified as one of the candidate proteins of the autoantigen. SARS-CoV-induced cytokines interlekin-6 (IL-6) and INF $\gamma$ stimulate surface expression and raft distribution of annexin A2 in human lung type II epithelial A549 cells and increase the binding capability of anti-S2 antibodies to human lung epithelial cells. The upregulated expression and raft targeting of annexin A2 and the cross-reactivity of anti-S2 antibodies to annexin A2 may contribute to the pathogenesis of SARS disease [232].

Rhinovirus serotype 39 colocalizes with Src kinases, $\mathrm{PI} 3 \mathrm{~K}$, and the serine threonine kinase Akt in membrane rafts in the context of virus infection. Src and PI3K are upstream activators of Akt and the interleukin-8 (IL-8) promoter. Rhinovirus infection activates these kinases and sequent IL-8 expression, which exacerbates asthma and chronic obstructive pulmonary disease [233].

Persistent HPV infection results in transformation of epithelial cells that induces cellular polarity disturbance, which is implicated in MAL and BENE, components of the membrane raft's machinery for apical sorting of membrane proteins. Down-regulation of MAL and BENE genes in the context of HPV infection may play an important role in development of human cervical squamous cell cancer [112]. The "early" gene oncoproteins E6 and E7 of high-risk HPV are known to be invariably expressed in cervical cancers by inducing several signal alterations such as p53 inactivation, apoptosis suppression, telomerase activation, and cell adhesion disruption [234]. The additional oncoprotein E5 of high-risk HPV type 16 increases expression and association of both GM1 and caveolin-1, components of membrane rafts, on the cell surface. This up-regulation of membrane rafts helps HPV immune evasion by suppression of cytotoxic $\mathrm{T}$ lymphocytes and enhances proliferative signaling of epidermal growth factor (EGF) possibly through localization of the EGF receptor with membrane rafts [235].

\section{Role of Membrane Rafts in Prion Infection}

Involvement of membrane rafts in infectious particle prion (PrP) infection has been reported [236-242]. PrP is an infectious protein that does not have a genome, unlike viruses. $\mathrm{PrP}^{\mathrm{Sc}}$, the protease-resistant isoform of the host normal prion protein $\mathrm{PrP}^{\mathrm{c}}$, is the infectious component causing fetal neurodegenerative transmissible spongiform encephalopathies, called Creutzfeldt-Jakob disease in humans. $\operatorname{PrP}^{\mathrm{c}}$, which contains a conserved $\mathrm{N}$-terminal cationic domain that stimulates a raft-dependent pathway, internalizes in neuroblastoma $\mathrm{N} 2$ a cells through a clathrin-independent pathway associated with Arf6 [241] and raft-dependent macropinocytosis [240]. On the other hand, $\operatorname{PrP}^{\mathrm{c}}$ internalizes in Fischer rat thyroid (FRT) cells by cooperation of clathrin-dependent and raft-dependent pathways. This internalization does not affect caveolin expression in FRT cells, which do not express caveolin-1 and do not have any caveolae. These findings indicate that pathways of $\operatorname{PrP}^{\mathrm{c}}$ internalization are dependent on cell type and that the raft-dependent pathway distinctly differs from the caveola-dependent pathway [242]. Association of $\operatorname{PrP}^{C}$ with cholesterol-enriched membrane rafts enhances correct protein folding of $\operatorname{PrP}^{\mathrm{c}}$ conformation. Cholesterol 
TABLE 1: Function of membrane rafts in enveloped DNA viruses.

\begin{tabular}{|c|c|c|}
\hline Family & Virus & Process \\
\hline \multirow{10}{*}{ Herpesviridae } & $\begin{array}{l}\text { Epstein-Barr virus } \\
\text { (EBV) }\end{array}$ & Entry \\
\hline & & $\begin{array}{c}\text { Entry } \\
\text { Assembly }\end{array}$ \\
\hline & Herpes simplex virus-1 & Progeny virus \\
\hline & & $\begin{array}{l}\text { Alzheimer's disease } \\
\text { susceptibility }\end{array}$ \\
\hline & $\begin{array}{l}\text { Porcine herpesvirus-1 } \\
\text { (pseudorabies virus) }\end{array}$ & $\begin{array}{c}\text { Entry } \\
\text { Viral spread in neurons }\end{array}$ \\
\hline & $\begin{array}{c}\text { Human herpesvirus-6 } \\
\text { (HHV-6) }\end{array}$ & $\begin{array}{c}\text { Entry } \\
\text { Assembly }\end{array}$ \\
\hline & & Entry \\
\hline & $\begin{array}{l}\text { Human herpesvirus-8 } \\
\text { (HHV-8) }\end{array}$ & $\begin{array}{l}\text { Viral immune evasion } \\
\text { Persistent infection }\end{array}$ \\
\hline & $\begin{array}{c}\text { Murine } \\
\text { cytomegalovirus } \\
(\mathrm{MCMV})\end{array}$ & Assembly \\
\hline & $\begin{array}{c}\text { Lymphotropic } \\
\text { herpesvirus saimiri } \\
\text { (HVS) }\end{array}$ & Lymphoma \\
\hline Poxviridae & Vaccinia virus & $\begin{array}{c}\text { Entry } \\
\text { Penetration }\end{array}$ \\
\hline
\end{tabular}

depletion, but not sphingolipid depletion, leads to abnormal protein folding from $\operatorname{PrP}^{\mathrm{C}}$ to $\operatorname{PrP}^{\mathrm{Sc}}$ [236-238]. GPI-anchored HSPG glypican-1 directly interacts with both $\operatorname{PrP}^{\mathrm{c}}$ and $\mathrm{PrP}^{\mathrm{Sc}}$ and targets these to membrane rafts. Targeting of both prions through glypican-1 facilitates favorable interaction of $\operatorname{PrP}^{\mathrm{Sc}}$ with $\operatorname{PrP}^{\mathrm{c}}$ within membrane rafts, which are believed to be the conversion sites of $\operatorname{PrP}^{\mathrm{c}}$ to $\operatorname{PrP}^{\mathrm{Sc}}$, suggesting a critical role of glypican-1 in the pathogenesis of prion disease [243]. $\operatorname{PrP}^{c}$ is associated with membrane rafts in membrane-derived microvesicles of human plasma that are important modulators of cell-to-cell communication. Membrane-derived microvesicles bearing $\operatorname{PrP}^{\mathrm{c}}$ within membrane rafts may contribute to intercellular diffusion, intracellular signaling, and neuroinvasion of $\operatorname{PrP}^{\mathrm{C}}$ [244]. The property of the GPI anchor attached to $\operatorname{PrP}^{\mathrm{Sc}}$ has been reported to affect the binding of $\mathrm{PrP}^{\mathrm{Sc}}$ to neurons, distribution to membrane rafts, and conversion of endogenous $\operatorname{PrP}^{c}$ in GT1 neuronal cells [245]. Moreover, the increased level of glycosphingolipid GM1 (an essential raft marker) on fibroblast cells by a mouse parvovirus (Parvoviridae) infection may promote prion infection through the incorporation of exogenous $\mathrm{PrP}^{\mathrm{Sc}}$ into membrane rafts [239].

\section{Conclusion}

Many studies have suggested the involvement of membrane rafts in cell entry, genome replication, assembly, budding, and virus-associated diseases of enveloped and nonenveloped viruses (summarized in Tables 1, 2, 3, and 4). Paradoxically, some recent studies have shown that membrane rafts are not necessarily required for efficient viral replication. For the virus entry process, many viruses use several dif-
TABLE 2: Function of membrane rafts in enveloped RNA viruses.

\begin{tabular}{|c|c|c|}
\hline Family & Virus & Process \\
\hline Arenaviridae & $\begin{array}{l}\text { Lymphocytic } \\
\text { choriomenin- } \\
\text { gitis virus } \\
\text { (LCMV) }\end{array}$ & Entry \\
\hline Coronaviridae & $\begin{array}{l}\text { SARS-CoV, } \\
\text { coronavirus }\end{array}$ & $\begin{array}{c}\text { Entry } \\
\text { Lung pathogenicity }\end{array}$ \\
\hline \multirow[t]{2}{*}{ Filoviridae } & Ebola virus & $\begin{array}{l}\text { Entry } \\
\text { Fusion } \\
\text { Assembly } \\
\text { Budding }\end{array}$ \\
\hline & Marburg virus & $\begin{array}{l}\text { Entry } \\
\text { Budding }\end{array}$ \\
\hline \multirow[t]{4}{*}{ Flaviviridae } & $\begin{array}{l}\text { Dengue virus } \\
\quad(\mathrm{DEN})\end{array}$ & $\begin{array}{c}\text { Entry } \\
\text { Viral RNA replication } \\
\text { ADE of viral infection } \\
\text { Antiapoptosis } \\
\text { Pathogenicity }\end{array}$ \\
\hline & $\begin{array}{c}\text { Japanese } \\
\text { encephalitis } \\
\text { virus } \\
\text { (JEV) }\end{array}$ & $\begin{array}{c}\text { Entry } \\
\text { Viral RNA replication } \\
\text { Progeny virus } \\
\text { production } \\
\text { Anti-apoptosis } \\
\text { Neuronal pathogenicity }\end{array}$ \\
\hline & $\begin{array}{l}\text { West Nile virus } \\
\text { (WNV) }\end{array}$ & $\begin{array}{c}\text { Entry } \\
\text { Basolateral } \\
\text { transportation } \\
\text { in endothelial cells } \\
\text { Viral spreads from the } \\
\text { blood } \\
\text { stream to the central } \\
\text { nervous } \\
\text { system and peripheral } \\
\text { tissues }\end{array}$ \\
\hline & $\begin{array}{l}\text { Human } \\
\text { hepatitis C } \\
\text { virus } \\
(\mathrm{HCV})\end{array}$ & $\begin{array}{c}\text { Entry } \\
\text { Vrial RNA replication } \\
\text { Progeny virus infectivity } \\
\text { Budding } \\
\text { MoDC maturation } \\
\text { Viral immune evasion } \\
\text { Persistent infection }\end{array}$ \\
\hline Orthomyxoviridae & Influenza virus & $\begin{array}{c}\text { Fusion } \\
\text { Assembly } \\
\text { Budding } \\
\text { Progeny virus infectivity } \\
\text { Apical targeting } \\
\text { Viral proton channel }\end{array}$ \\
\hline \multirow{3}{*}{ Paramyxoviridae } & Measles virus & $\begin{array}{c}\text { Assembly } \\
\text { Inflammatory response } \\
\text { Immunosuppression }\end{array}$ \\
\hline & $\begin{array}{c}\text { Newcastle } \\
\text { disease virus } \\
(\mathrm{NDV})\end{array}$ & $\begin{array}{c}\text { Assembly } \\
\text { Budding } \\
\text { Progeny virus infectivity }\end{array}$ \\
\hline & $\begin{array}{c}\text { Respiratory } \\
\text { syncytial virus } \\
\text { (RSV) }\end{array}$ & $\begin{array}{c}\text { Viral RNA replication } \\
\text { Assembly } \\
\text { Budding } \\
\text { Host immune response }\end{array}$ \\
\hline
\end{tabular}


TABle 2: Continued.

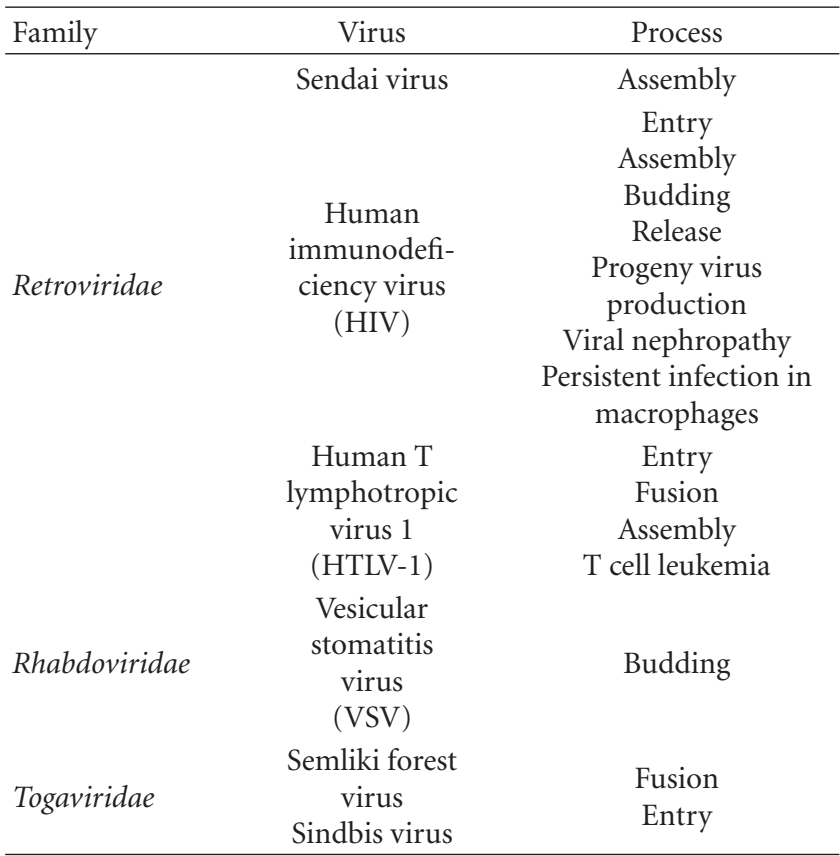

TABLE 3: Function of membrane rafts in nonenveloped DNA viruses.

\begin{tabular}{lcc}
\hline Family & Virus & Process \\
\hline Adenoviridae & $\begin{array}{c}\text { Species C human } \\
\text { adenovirus } \\
(\text { HAdV })\end{array}$ & Entry
\end{tabular}

\begin{tabular}{ccc} 
& $\begin{array}{c}\text { Simian virus } 40 \\
\text { (SV40) }\end{array}$ & Entry \\
Papovaviridae & BK virus & Entry \\
& JC virus & Entry \\
& Bovine papillomavirus & Entry \\
& Human papillomavirus & Entry \\
& $($ HPV $)$ & Immune evasion \\
Parvoviridae & Mouse parvovirus & Persistent infection \\
\hline
\end{tabular}

ferent pathways, not only caveola/raft-dependent but also clathrin-dependent or another endocytic pathway such as macropinocytosis. Additionally, the caveola-dependent pathway does not necessarily correspond to the raft-dependent one, suggesting the existence of other complicated pathways associated with caveolae and membrane rafts. For the assembly and budding processes of many enveloped viruses, membrane raft disruption on host cells facilitates formation and production of progeny virus particles with less infectivity and lower viral components. Also, membrane rafts are not necessarily essential for cellular membrane targeting of viral structural proteins. For virus assembly and budding, membrane rafts are more likely to provide progeny virus particles with greater infectivity because of the concentration and
TABLE 4: Function of membrane rafts in nonenveloped RNA viruses.

\begin{tabular}{lcc}
\hline Family & Virus & Process \\
\hline & Echovirus & Entry \\
types 1 and 11 & Entry \\
& Enterovirus & Entry \\
& Rhinovirus & Cellular kinase activation \\
& Coxsackie virus & Entry \\
& A9, B3 and B4 & \\
& & Entry \\
Reoviridae & Rotavirus & Assembly \\
& & Apical targeting \\
& & Golgi transport \\
& Bluetongue virus & Entry \\
& & Assembly \\
& & Membrane targeting
\end{tabular}

efficient incorporation of viral structural components from the assembly and budding sites to the virus particles. Similarly, concentration of viral polymerases into membrane rafts acts as a platform of more efficient replication and transcription of viral genomes. Furthermore, the use of several endocytic pathways provides an advantage for virus entry into a wider range of hosts, cell lines, and tissues or can allow the virus to be assigned to an alternative pathway when one pathway does not work. Concentration of viral fusion proteins in raft-associated receptors or caveola/raftdependent endocytosis may enhance membrane fusion between the virus and cell, leading to efficient release of viral internal proteins and genomes to the cytoplasm at an early stage of virus infection. Taken together, the results indicate that membrane rafts are not essential for viral life cycles. Viruses probably take advantage of membrane rafts for more efficiency of virus entry, viral genome replication, and virus particle production. Viruses also induce many raft-mediated cellular signals which relate to characteristic symptoms of the viral diseases.

Many studies on the involvement of membrane rafts in viral infection cycles and viral infectious diseases have been performed by classical approaches (cholesterol-disrupting reagent treatments, detergent-insoluble fractionization, and microscopic observation of colocalization with raft markers) and by recent molecular biological approaches (RNAi and dominant negative expression against representative raft components). However, since various types of microdomains, such as raft-dependent, caveola-dependent, cholesterol-dependent, and other specialized microdomains, have been shown to have independent heterogeneous properties, evaluation of respective functions of distinct membrane rafts and microdomains would be difficult by experiments using only common approaches to study membrane rafts. Further study will require new approaches for elucidating the functions of distinct membrane microdomains. An understanding of the role of membrane rafts in viral lifecycle may contribute to elucidation of essential cellular functions 
of membrane rafts and to development of new antiviral chemotherapy against viral replications and viral infectious diseases.

\section{References}

[1] L. Pelkmans and A. Helenius, "Endocytosis via caveolae," Traffic, vol. 3, no. 5, pp. 311-320, 2002.

[2] L. Pelkmans, "Secrets of caveolae- and lipid raft-mediated endocytosis revealed by mammalian viruses," Biochimica et Biophysica Acta, vol. 1746, no. 3, pp. 295-304, 2005.

[3] L. J. Pike, "Rafts defined: a report on the Keystone symposium on lipid rafts and cell function," Journal of Lipid Research, vol. 47, no. 7, pp. 1597-1598, 2006.

[4] K. Quirin, B. Eschli, I. Scheu, L. Poort, J. Kartenbeck, and A. Helenius, "Lymphocytic choriomeningitis virus uses a novel endocytic pathway for infectious entry via late endosomes," Virology, vol. 378, no. 1, pp. 21-33, 2008.

[5] R. Nomura, A. Kiyota, E. Suzaki et al., "Human coronavirus $229 \mathrm{E}$ binds to CD13 in rafts and enters the cell through caveolae," Journal of Virology, vol. 78, no. 16, pp. 8701-8708, 2004.

[6] E. B. Thorp and T. M. Gallagher, "Requirements for CEACAMs and cholesterol during murine coronavirus cell entry," Journal of Virology, vol. 78, no. 6, pp. 2682-2692, 2004.

[7] K. S. Choi, H. Aizaki, and M. M. C. Lai, "Murine coronavirus requires lipid rafts for virus entry and cell-cell fusion but not for virus release," Journal of Virology, vol. 79, no. 15, pp. 9862-9871, 2005.

[8] G. M. Li, Y. G. Li, M. Yamate, S. M. Li, and K. Ikuta, "Lipid rafts play an important role in the early stage of severe acute respiratory syndrome-coronavirus life cycle," Microbes and Infection, vol. 9, no. 1, pp. 96-102, 2007.

[9] H. Wang, P. Yang, K. Liu et al., "SARS coronavirus entry into host cells through a novel clathrin- and caveolae-independent endocytic pathway," Cell Research, vol. 18, no. 2, pp. 290-301, 2008.

[10] Y. Lu, D. X. Liu, and J. P. Tam, "Lipid rafts are involved in SARS-CoV entry into Vero E6 cells," Biochemical and Biophysical Research Communications, vol. 369, no. 2, pp. 344349, 2008.

[11] E. Van Hamme, H. L. Dewerchin, E. Cornelissen, B. Verhasselt, and H. J. Nauwynck, "Clathrin- and caveolae-independent entry of feline infectious peritonitis virus in monocytes depends on Dynamin," Journal of General Virology, vol. 89, no. 9, pp. 2147-2158, 2008.

[12] S. Bavari, C. M. Bosio, E. Wiegand et al., "Lipid raft microdomains: a gateway for compartmentalized trafficking of Ebola and Marburg viruses," Journal of Experimental Medicine, vol. 195, no. 5, pp. 593-602, 2002.

[13] M. S. Freitas, C. Follmer, L. T. Costa et al., "Measuring the strength of interaction between the Ebola fusion peptide and lipid rafts: implications for membrane fusion and virus infection," PLoS ONE, vol. 6, no. 1, article e15756, 2011.

[14] C. L. Hunt, A. A. Kolokoltsov, R. A. Davey, and W. Maury, "The Tyro3 receptor kinase Axl enhances macropinocytosis of Zaire ebolavirus," Journal of Virology, vol. 85, no. 1, pp. 334-347, 2011.

[15] M. J. Aman, C. M. Bosio, R. G. Panchal, J. C. Burnett, A. Schmaljohn, and S. Bavari, "Molecular mechanisms of filovirus cellular trafficking," Microbes and Infection, vol. 5, no. 7, pp. 639-649, 2003.
[16] G. R. Medigeshi, A. J. Hirsch, D. N. Streblow, J. NikolichZugich, and J. A. Nelson, "West Nile virus entry requires cholesterol-rich membrane microdomains and is independent of $\alpha \mathrm{v} \beta 3$ integrin," Journal of Virology, vol. 82, no. 11, pp. 52125219, 2008.

[17] C. J. Lee, C. L. Liao, and Y. L. Lin, "Flavivirus activates phosphatidylinositol 3-kinase signaling to block caspase-dependent apoptotic cell death at the early stage of virus infection," Journal of Virology, vol. 79, no. 13, pp. 8388-8399, 2005.

[18] J. Reyes-Del Valle, S. Chávez-Salinas, F. Medina, and R. M. Del Angel, "Heat shock protein 90 and heat shock protein 70 are components of dengue virus receptor complex in human cells," Journal of Virology, vol. 79, no. 8, pp. 4557-4567, 2005.

[19] C. J. Lee, H. R. Lin, C. L. Liao, and Y. G. Lin, "Cholesterol effectively blocks entry of flavivirus," Journal of Virology, vol. 82, no. 13, pp. 6470-6480, 2008.

[20] H. Puerta-Guardo, C. Mosso, F. Medina, F. Liprandi, J. E. Ludert, and R. M. del Angel, "Antibody-dependent enhancement of dengue virus infection in U937 cells requires cholesterol-rich membrane microdomains," Journal of General Virology, vol. 91, no. 2, pp. 394-403, 2010.

[21] S. Das, S. Chakraborty, and A. Basu, "Critical role of lipid rafts in virus entry and activation of phosphoinositide 3' kinase/Akt signaling during early stages of Japanese encephalitis virus infection in neural stem/progenitor cells," Journal of Neurochemistry, vol. 115, no. 2, pp. 537-549, 2010.

[22] S. B. Kapadia, H. Barth, T. Baumert, J. A. McKeating, and F. V. Chisari, "Initiation of hepatitis $\mathrm{C}$ virus infection is dependent on cholesterol and cooperativity between CD81 and scavenger receptor B type I," Journal of Virology, vol. 81, no. 1, pp. 374-383, 2007.

[23] C. Voisset, M. Lavie, F. Helle et al., "Ceramide enrichment of the plasma membrane induces CD81 internalization and inhibits hepatitis C virus entry," Cellular Microbiology, vol. 10, no. 3, pp. 606-617, 2008.

[24] J. D. Fingeroth, J. J. Weis, and T. F. Tedder, "Epstein-Barr virus receptor of human B lymphocytes is the C3d receptor CR2," Proceedings of the National Academy of Sciences of the United States of America, vol. 81, no. 14 I, pp. 4510-4514, 1984.

[25] A. Cherukuri, R. H. Carter, S. Brooks et al., "B cell signaling is regulated by induced palmitoylation of CD81," Journal of Biological Chemistry, vol. 279, no. 30, pp. 31973-31982, 2004.

[26] F. C. Bender, J. C. Whitbeck, M. P. De Leon, H. Lou, R. J. Eisenberg, and G. H. Cohen, "Specific association of glycoprotein B with lipid rafts during herpes simplex virus entry," Journal of Virology, vol. 77, no. 17, pp. 9542-9552, 2003.

[27] T. Gianni, V. Gatta, and G. Campadelli-Fiume, " $\alpha_{v} \beta_{3}$-integrin routes herpes simplex virus to an entry pathway dependent on cholesterol-rich lipid rafts and dynamin2," Proceedings of the National Academy of Sciences of the United States of America, vol. 107, no. 51, pp. 22260-22265, 2010.

[28] A. S. Desplanques, H. J. Nauwynck, D. Vercauteren, T. Geens, and H. W. Favoreel, "Plasma membrane cholesterol is required for efficient pseudorabies virus entry," Virology, vol. 376, no. 2, pp. 339-345, 2008.

[29] H. Tang, A. Kawabata, M. Takemoto, K. Yamanishi, and Y. Mori, "Human herpesvirus-6 infection induces the reorganization of membrane microdomains in target cells, which are required for virus entry," Virology, vol. 378, no. 2, pp. 265271, 2008. 
[30] H. Raghu, N. Sharma-Walia, M. V. Veettil et al., "Lipid rafts of primary endothelial cells are essential for Kaposi's sarcoma-associated herpesvirus/human herpesvirus 8-induced phosphatidylinositol 3-kinase and RhoA-GTPases critical for microtubule dynamics and nuclear delivery of viral DNA but dispensable for binding and entry," Journal of Virology, vol. 81, no. 15, pp. 7941-7959, 2007.

[31] W. Greene and S. J. Gao, "Actin dynamics regulate multiple endosomal steps during Kaposi's sarcoma-associated herpesvirus entry and trafficking in endothelial cells," PLoS Pathogens, vol. 5, no. 7, Article ID e1000512, 2009.

[32] D. Z. Cleverley, H. M. Geller, and J. Lenard, "Characterization of cholesterol-free insect cells infectible by baculoviruses: effects of cholesterol on VSV fusion and infectivity and on cytotoxicity induced by influenza M2 protein," Experimental Cell Research, vol. 233, no. 2, pp. 288-296, 1997.

[33] S. B. Sieczkarski and G. R. Whittaker, "Influenza virus can enter and infect cells in the absence of clathrin-mediated endocytosis," Journal of Virology, vol. 76, no. 20, pp. 1045510464, 2002.

[34] M. Takeda, G. P. Leser, C. J. Russell, and R. A. Lamb, "Influenza virus hemagglutinin concentrates in lipid raft microdomains for efficient viral fusion," Proceedings of the National Academy of Sciences of the United States of America, vol. 100, no. 25, pp. 14610-14617, 2003.

[35] M. Lakadamyali, M. J. Rust, and X. Zhuang, "Endocytosis of influenza viruses," Microbes and Infection, vol. 6, no. 10, pp. 929-936, 2004.

[36] A. E. Smith and A. Helenius, "How viruses enter animal cells," Science, vol. 304, no. 5668, pp. 237-242, 2004.

[37] F. De Conto, S. Covan, M. C. Arcangeletti et al., "Differential infectious entry of human influenza A/NWS/33 virus (H1N1) in mammalian kidney cells," Virus Research, vol. 155, no. 1, pp. 221-230, 2011.

[38] C. S. Chung, C. Y. Huang, and W. Chang, "Vaccinia virus penetration requires cholesterol and results in specific viral envelope proteins associated with lipid rafts," Journal of Virology, vol. 79, no. 3, pp. 1623-1634, 2005.

[39] S. Mañes, G. Del Real, R. A. Lacalle et al., "Membrane raft microdomains mediate lateral assemblies required for HIV-1 infection," EMBO Reports, vol. 1, no. 2, pp. 190-196, 2000.

[40] S. M. Campbell, S. M. Crowe, and J. Mak, "Lipid rafts and HIV-1: from viral entry to assembly of progeny virions," Journal of Clinical Virology, vol. 22, no. 3, pp. 217-227, 2001.

[41] Z. Liao, D. R. Graham, and J. E. K. Hildreth, "Lipid rafts and HIV pathogenesis: virion-associated cholesterol is required for fusion and infection of susceptible cells," AIDS Research and Human Retroviruses, vol. 19, no. 8, pp. 675-687, 2003.

[42] N. Huarte, M. Lorizate, R. Kunert, and J. L. Nieva, "Lipid modulation of membrane-bound epitope recognition and blocking by HIV-1 neutralizing antibodies," FEBS Letters, vol. 582, no. 27, pp. 3798-3804, 2008.

[43] G. C. Carter, L. Bernstone, D. Sangani, J. W. Bee, T. Harder, and W. James, "HIV entry in macrophages is dependent on intact lipid rafts," Virology, vol. 386, no. 1, pp. 192-202, 2009.

[44] H. Kamiyama, H. Yoshii, Y. Tanaka, H. Sato, N. Yamamoto, and Y. Kubo, "Raft localization of CXCR4 is primarily required for X4-tropic human immunodeficiency virus type 1 infection," Virology, vol. 386, no. 1, pp. 23-31, 2009.

[45] P. E. Ray, "Shiga-like toxins and HIV-1 go through glycosphingolipids and lipid rafts in renal cells," Kidney International, vol. 75, no. 11, pp. 1135-1137, 2009.
[46] K. Niyogi and J. E. K. Hildreth, "Characterization of new syncytium-inhibiting monoclonal antibodies implicates lipid rafts in human T-cell leukemia virus type 1 syncytium formation," Journal of Virology, vol. 75, no. 16, pp. 7351-7361, 2001.

[47] M. M. Wielgosz, D. A. Rauch, K. S. Jones, F. W. Ruscetti, and L. Ratner, "Cholesterol dependence of HTLV-I infection," AIDS Research and Human Retroviruses, vol. 21, no. 1, pp. 43-50, 2005.

[48] M. C. Kielian and A. Helenius, "Role of cholesterol in fusion of Semliki Forest virus with membranes," Journal of Virology, vol. 52, no. 1, pp. 281-283, 1984.

[49] T. Phalen and M. Kielian, "Cholesterol is required for infection by Semliki Forest virus," Journal of Cell Biology, vol. 112, no. 4, pp. 615-623, 1991.

[50] A. Ahn, D. L. Gibbons, and M. Kielian, "The fusion peptide of Semliki Forest virus associates with sterol-rich membrane domains," Journal of Virology, vol. 76, no. 7, pp. 3267-3275, 2002.

[51] B. L. Waarts, R. Bittman, and J. Wilschut, "Sphingolipid and cholesterol dependence of alphavirus membrane fusion: lack of correlation with lipid raft formation in target liposomes," Journal of Biological Chemistry, vol. 277, no. 41, pp. 3814138147, 2002.

[52] Y. E. Lu, T. Cassese, and M. Kielian, "The cholesterol requirement for sindbis virus entry and exit and characterization of a spike protein region involved in cholesterol dependence," Journal of Virology, vol. 73, no. 5, pp. 4272-4278, 1999.

[53] B. J. Nichols, A. K. Kenworthy, R. S. Polishchuk et al., "Rapid cycling of lipid raft markers between the cell surface and golgi complex," Journal of Cell Biology, vol. 152, no. 3, pp. 529-541, 2001.

[54] S. Y. Chan, R. F. Speck, M. C. Ma, and M. A. Goldsmith, "Distinct mechanisms of entry by envelope glycoproteins of Marburg and Ebola (Zaire) viruses," Journal of Virology, vol. 74, no. 10, pp. 4933-4937, 2000.

[55] R. J. Wool-Lewis and P. Bates, "Characterization of Ebola virus entry by using pseudotyped viruses: identification of receptor-deficient cell lines," Journal of Virology, vol. 72, no. 4, pp. 3155-3160, 1998.

[56] J. J. H. Chu and M. L. Ng, "Interaction of West Nile virus with $\alpha \mathrm{v} \beta 3$ integrin mediates virus entry into cells," Journal of Biological Chemistry, vol. 279, no. 52, pp. 54533-54541, 2004.

[57] J. J. H. Chu and M. L. Ng, "Infectious entry of West Nile virus occurs through a clathrin-mediated endocytic pathway," Journal of Virology, vol. 78, no. 19, pp. 10543-10555, 2004.

[58] E. Navarro-Sanchez, R. Altmeyer, A. Amara et al., "Dendritic-cell-specific ICAM3-grabbing non-integrin is essential for the productive infection of human dendritic cells by mosquito-cell-derived dengue viruses," EMBO Reports, vol. 4, no. 7, pp. 723-728, 2003.

[59] Y. Chen, T. Maguire, R. E. Hileman et al., "Dengue virus infectivity depends on envelope protein binding to target cell heparan sulfate," Nature Medicine, vol. 3, no. 8, pp. 866-871, 1997.

[60] C. Aoki, K. I. P. J. Hidari, S. Itonori et al., "Identification and characterization of carbohydrate molecules in mammalian cells recognized by dengue virus type 2," Journal of Biochemistry, vol. 139, no. 3, pp. 607-614, 2006.

[61] E. Caparrós, P. Munoz, E. Sierra-Filardi et al., "DC-SIGN ligation on dendritic cells results in ERK and PI3K activation and modulates cytokine production," Blood, vol. 107, no. 10, pp. 3950-3958, 2006. 
[62] S. Das, S. V. Laxminarayana, N. Chandra, V. Ravi, and A. Desai, "Heat shock protein 70 on Neuro2a cells is a putative receptor for Japanese encephalitis virus," Virology, vol. 385, no. 1, pp. 47-57, 2009.

[63] Y. J. Chien, W. J. Chen, W. L. Hsu, and S. S. Chiou, "Bovine lactoferrin inhibits Japanese encephalitis virus by binding to heparan sulfate and receptor for low density lipoprotein," Virology, vol. 379, no. 1, pp. 143-151, 2008.

[64] M. Birkenbach, X. Tong, L. E. Bradbury, T. F. Tedder, and E. Kieff, "Characterization of an Epstein-Barr virus receptor on human epithelial cells," Journal of Experimental Medicine, vol. 176, no. 5, pp. 1405-1414, 1992.

[65] R. I. Montgomery, M. S. Warner, B. J. Lum, and P. G. Spear, "Herpes simplex virus-1 entry into cells mediated by a novel member of the TNF/NGF receptor family," Cell, vol. 87, no. 3, pp. 427-436, 1996.

[66] R. J. Geraghty, C. Krummenacher, G. H. Cohen, R. J. Eisenberg, and P. G. Spear, "Entry of alphaherpesviruses mediated by poliovirus receptor-related protein 1 and poliovirus receptor," Science, vol. 280, no. 5369, pp. 1618-1620, 1998.

[67] T. Satoh, J. Arii, T. Suenaga et al., "PILR $\alpha$ is a herpes simplex virus-1 entry coreceptor that associates with glycoprotein B," Cell, vol. 132, no. 6, pp. 935-944, 2008.

[68] D. Shukla, J. Liu, P. Blaiklock et al., "A novel role for 3-Osulfated heparan sulfate in herpes simplex virus 1 entry," Cell, vol. 99, no. 1, pp. 13-22, 1999.

[69] F. C. Bender, J. C. Whitbeck, H. Lou, G. H. Cohen, and R. J. Eisenberg, "Herpes simplex virus glycoprotein B binds to cell surfaces independently of heparan sulfate and blocks virus entry," Journal of Virology, vol. 79, no. 18, pp. 11588-11597, 2005.

[70] D. F. Legler, O. Micheau, M. A. Doucey, J. Tschopp, and C. Bron, "Recruitment of TNF receptor 1 to lipid rafts is essential for TNF $\alpha$-mediated NF- $\kappa \mathrm{B}$ activation," Immunity, vol. 18 , no. 5, pp. 655-664, 2003.

[71] C. L. Chu, J. A. Buczek-Thomas, and M. A. Nugent, "Heparan sulphate proteoglycans modulate fibroblast growth factor-2 binding through a lipid raft-mediated mechanism," Biochemical Journal, vol. 379, no. 2, pp. 331-341, 2004.

[72] Y. Suzuki, T. Ito, T. Suzuki et al., "Sialic acid species as a determinant of the host range of influenza A viruses," Journal of Virology, vol. 74, no. 24, pp. 11825-11831, 2000.

[73] M. Matrosovich, T. Suzuki, Y. Hirabayashi, W. Garten, R. G. Webster, and H. D. Klenk, "Gangliosides are not essential for influenza virus infection," Glycoconjugate Journal, vol. 23, no. 1-2, pp. 107-113, 2006.

[74] C. Schroeder, H. Heider, E. Möncke-Buchner, and T. I. Lin, "The influenza virus ion channel and maturation cofactor M2 is a cholesterol-binding protein," European Biophysics Journal, vol. 34, no. 1, pp. 52-66, 2005.

[75] A. Cooper and Y. Shaul, "Clathrin-mediated endocytosis and lysosomal cleavage of hepatitis B virus capsid-like core particles," Journal of Biological Chemistry, vol. 281, no. 24, pp. 16563-16569, 2006.

[76] H. Deng, R. Liu, W. Ellmeier et al., "Identification of a major co-receptor for primary isolates of HIV-1," Nature, vol. 381, no. 6584, pp. 661-666, 1996.

[77] T. Dragic, V. Litwin, G. P. Allaway et al., "HIV-1 entry into $\mathrm{CD}^{4+}$ cells is mediated by the chemokine receptor CC-CKR5," Nature, vol. 381, no. 6584, pp. 667-673, 1996.

[78] D. R. Briggs, D. L. Tuttle, J. W. Sleasman, and M. M. Goodenow, "Envelope V3 amino acid sequence predicts HIV-1 phenotype (co-receptor usage and tropism for macrophages)," AIDS, vol. 14, no. 18, pp. 2937-2939, 2000.
[79] S. Mañes, E. Mira, C. Gómez-Moutón et al., "Membrane raft microdomains mediate front-rear polarity in migrating cells," EMBO Journal, vol. 18, no. 22, pp. 6211-6220, 1999.

[80] S. L. Kozak, J. M. Heard, and D. Kabat, "Segregation of CD4 and CXCR4 into distinct lipid microdomains in T lymphocytes suggests a mechanism for membrane destabilization by human immunodeficiency virus," Journal of Virology, vol. 76, no. 4, pp. 1802-1815, 2002.

[81] G. Gaibelet, T. Planchenault, S. Mazères et al., "CD4 and CCR5 constitutively interact at the plasma membrane of living cells: a confocal fluorescence resonance energy transferbased approach," Journal of Biological Chemistry, vol. 281, no. 49, pp. 37921-37929, 2006.

[82] J. Fantini, D. G. Cook, N. Nathanson, S. L. Spitalnik, and F. Gonzalez-Scarano, "Infection of colonic epithelial cell lines by type 1 human immunodeficiency virus is associated with cell surface expression of galactosylceramide, a potential alternative gp120 receptor," Proceedings of the National Academy of Sciences of the United States of America, vol. 90, no. 7, pp. 2700-2704, 1993.

[83] D. Hammache, G. Piéroni, N. Yahi et al., "Specific interaction of HIV-1 and HIV-2 surface envelope glycoproteins with monolayers of galactosylceramide and ganglioside GM3," Journal of Biological Chemistry, vol. 273, no. 14, pp. 79677971, 1998.

[84] A. Puri, P. Hug, K. Jernigan et al., "The neutral glycosphingolipid globotriaosylceramide promotes fusion mediated by a CD4-dependent CXCR4-utilizing HIV type 1 envelope glycoprotein," Proceedings of the National Academy of Sciences of the United States of America, vol. 95, no. 24, pp. 1443514440, 1998.

[85] S. S. Rawat, M. Viard, S. A. Gallo, R. Blumenthal, and A. Puri, "Sphingolipids, cholesterol, and HIV-1: a paradigm in viral fusion," Glycoconjugate Journal, vol. 23, no. 3-4, pp. 189-197, 2006.

[86] S. C. Chan, S. Y. Lo, J. W. Liou et al., "Visualization of the structures of the hepatitis C virus replication complex," Biochemical and Biophysical Research Communications, vol. 404, no. 1, pp. 574-578, 2011.

[87] E. G. Argyris, E. Acheampong, G. Nunnari, M. Mukhtar, K. J. Williams, and R. J. Pomerantz, "Human immunodeficiency virus type 1 enters primary human brain microvascular endothelial cells by a mechanism involving cell surface proteoglycans independent of lipid rafts," Journal of Virology, vol. 77, no. 22, pp. 12140-12151, 2003.

[88] N. Manel, F. J. Kim, S. Kinet, N. Taylor, M. Sitbon, and J. L. Battini, "The ubiquitous glucose transporter GLUT-1 is a receptor for HTLV," Cell, vol. 115, no. 4, pp. 449-459, 2003.

[89] A. Kumar, Y.-P. Xiao, P. J. Laipis, B. S. Fletcher, and S. C. Frost, "Glucose deprivation enhances targeting of GLUT1 to lipid rafts in 3T3-L1 adipocytes," American Journal of Physiology, vol. 286, no. 4, pp. E568-E576, 2004.

[90] M. Umashankar, C. Sánchez-San Martín, M. Liao et al., "Differential cholesterol binding by class II fusion proteins determines membrane fusion properties," Journal of Virology, vol. 82, no. 18, pp. 9245-9253, 2008.

[91] M. Colin, L. Mailly, S. Rogée, and J. C. D’Halluin, “Efficient species C HAdV infectivity in plasmocytic cell lines using a clathrin-independent lipid raft/caveola endocytic route," Molecular Therapy, vol. 11, no. 2, pp. 224-236, 2005.

[92] S. Rogée, E. Grellier, C. Bernard et al., "Intracellular trafficking of a fiber-modified adenovirus using lipid raft/caveolae endocytosis," Molecular Therapy, vol. 15, no. 11, pp. 19631972, 2007. 
[93] K. Triantafilou, D. Fradelizi, K. Wilson, and M. Triantafilou, "GRP78, a coreceptor for coxsackievirus A9, interacts with major histocompatibility complex class I molecules which mediate virus internalization," Journal of Virology, vol. 76, no. 2, pp. 633-643, 2002.

[94] K. Triantafilou and M. Triantafilou, "Lipid raft microdomains: key sites for Coxsackievirus A9 infectious cycle," Viro$\log y$, vol. 317, no. 1, pp. 128-135, 2003.

[95] K. Triantafilou and M. Triantafilou, "Lipid-raft-dependent Coxsackievirus B4 internalization and rapid targeting to the Golgi," Virology, vol. 326, no. 1, pp. 6-19, 2004.

[96] K. P. Patel, C. B. Coyne, and J. M. Bergelson, "Dynaminand lipid raft-dependent entry of decay-accelerating factor (DAF)-binding and non-DAF-binding coxsackieviruses into nonpolarized cells," Journal of Virology, vol. 83, no. 21, pp. 11064-11077, 2009.

[97] V. Marjomäki, V. Pietiäinen, H. Matilainen et al., "Internalization of echovirus 1 in caveolae," Journal of Virology, vol. 76, no. 4, pp. 1856-1865, 2002.

[98] A. D. Stuart, H. E. Eustace, T. A. McKee, and T. D. K. Brown, "A novel cell entry pathway for a DAF-using human enterovirus is dependent on lipid rafts," Journal of Virology, vol. 76, no. 18, pp. 9307-9322, 2002.

[99] V. Pietiäinen, V. Marjomäki, P. Upla, L. Pelkmans, A. Helenius, and T. Hyypiä, "Echovirus 1 endocytosis into caveosomes requires lipid rafts, dynamin II, and signaling events," Molecular Biology of the Cell, vol. 15, no. 11, pp. 4911-4925, 2004.

[100] P. Upla, V. Marjomäki, P. Kankaanpää et al., "Clustering induces a lateral redistribution of $\alpha 2 \beta 1$ integrin from membrane rafts to caveolae and subsequent protein kinase Cdependent internalization," Molecular Biology of the Cell, vol. 15, no. 2, pp. 625-636, 2004.

[101] V. M. Pietiäinen, V. Marjomäki, J. Heino, and T. Hyypiä, "Viral entry, lipid rafts and caveosomes," Annals of Medicine, vol. 37, no. 6, pp. 394-403, 2005.

[102] M. Karjalainen, E. Kakkonen, P. Upla et al., "A raft-derived, pak1-regulated entry participates in $\alpha 2 \beta 1$ integrin-dependent sorting to caveosomes," Molecular Biology of the Cell, vol. 19, no. 7, pp. 2857-2869, 2008.

[103] H. Grassmé, A. Riehle, B. Wilker, and E. Gulbins, "Rhinoviruses infect human epithelial cells via ceramide-enriched membrane platforms," Journal of Biological Chemistry, vol. 280, no. 28, pp. 26256-26262, 2005.

[104] S. Eash, W. Querbes, and W. J. Atwood, "Infection of Vero cells by BK virus is dependent on caveolae," Journal of Viro$\log y$, vol. 78, no. 21, pp. 11583-11590, 2004.

[105] S. Eash and W. J. Atwood, "Involvement of cytoskeletal components in BK virus infectious entry," Journal of Virology, vol. 79, no. 18, pp. 11734-11741, 2005.

[106] T. Moriyama, J. P. Marquez, T. Wakatsuki, and A. Sorokin, "Caveolar endocytosis is critical for BK virus infection of human renal proximal tubular epithelial cells," Journal of Virology, vol. 81, no. 16, pp. 8552-8562, 2007.

[107] V. Laniosz, K. A. Holthusen, and P. I. Meneses, "Bovine papillomavirus type 1: from clathrin to caveolin," Journal of Virology, vol. 82, no. 13, pp. 6288-6298, 2008.

[108] M. G. Lyman, D. Curanovic, and L. W. Enquist, "Targeting of pseudorabies virus structural proteins to axons requires association of the viral Us9 protein with lipid rafts," PLoS Pathogens, vol. 4, no. 5, article e1000065, 2008.
[109] Y. Matsushima, H. Fukasawa, Y. Endo, Y. Hashimoto, and K. Shudo, "Enhancement of human papillomavirus type 18 gene expression in HeLa cells by 12-O-tetradecanoylphorbol13-acetate, 3 $\beta, 5 \alpha$-dihydroxycholestan-6-one, and cholesterol," Biological and Pharmaceutical Bulletin, vol. 17, no. 9, pp. 1292-1295, 1994.

[110] H. C. Selinka, T. Giroglou, and M. Sapp, "Analysis of the infectious entry pathway of human papillomavirus type 33 pseudovirions," Virology, vol. 299, no. 2, pp. 279-287, 2002.

[111] L. Bousarghin, A. Touzé, P. Y. Sizaret, and P. Coursaget, "Human papillomavirus types 16, 31, and 58 use different endocytosis pathways to enter cells," Journal of Virology, vol. 77, no. 6, pp. 3846-3850, 2003.

[112] M. Hatta, H. Nagai, K. Okino et al., "Down-regulation of members of glycolipid-enriched membrane raft gene family, MAL and BENE, in cervical squamous cell cancers," Journal of Obstetrics and Gynaecology Research, vol. 30, no. 1, pp. 5358, 2004.

[113] P. L. Hindmarsh and L. A. Laimins, "Mechanisms regulating expression of the HPV $31 \mathrm{~L} 1$ and L2 capsid proteins and pseudovirion entry," Virology Journal, vol. 4, article 19, 2007.

[114] J. L. Smith, S. K. Campos, and M. A. Ozbun, "Human papillomavirus type 31 uses a caveolin 1- and dynamin 2-mediated entry pathway for infection of human keratinocytes," Journal of Virology, vol. 81, no. 18, pp. 9922-9931, 2007.

[115] J. L. Smith, S. K. Campos, A. Wandinger-Ness, and M. A. Ozbun, "Caveolin-1-dependent infectious entry of human papillomavirus type 31 in human keratinocytes proceeds to the endosomal pathway for $\mathrm{pH}$-dependent uncoating," Journal of Virology, vol. 82, no. 19, pp. 9505-9512, 2008.

[116] G. Spoden, K. Freitag, M. Husmann et al., "Clathrin- and caveolin-independent entry of human papillomavirus type 16-Involvement of tetraspanin-enriched microdomains (TEMs)," PLoS ONE, vol. 3, no. 10, Article ID e3313, 2008.

[117] W. Querbes, B. A. O’Hara, G. Williams, and W. J. Atwood, "Invasion of host cells by JC virus identifies a novel role for caveolae in endosomal sorting of noncaveolar ligands," Journal of Virology, vol. 80, no. 19, pp. 9402-9413, 2006.

[118] E. Stang, J. Kartenbeck, and R. G. Parton, "Major histocompatibility complex class I molecules mediate association of SV40 with caveolae," Molecular Biology of the Cell, vol. 8, no. 1, pp. 47-57, 1997.

[119] H. A. Anderson, Y. Chen, and L. C. Norkin, "MHC class I molecules are enriched in caveolae but do not enter with simian virus 40," Journal of General Virology, vol. 79, no. 6, pp. 1469-1477, 1998.

[120] R. G. Parton and M. Lindsay, "Exploitation of major histocompatibility complex class I molecules and caveolae by simian virus 40," Immunological Reviews, vol. 168, pp. 23-31, 1999.

[121] L. Pelkmans, J. Kartenbeck, and A. Helenius, "Caveolar endocytosis of simian virus 40 reveals a new two-step vesiculartransport pathway to the ER," Nature Cell Biology, vol. 3, no. 5, pp. 473-483, 2001.

[122] L. C. Norkin, H. A. Anderson, S. A. Wolfrom, and A. Oppenheim, "Caveolar endocytosis of simian virus 40 is followed by brefeldin A-sensitive transport to the endoplasmic reticulum, where the virus disassembles," Journal of Virology, vol. 76, no. 10, pp. 5156-5166, 2002.

[123] L. Pelkmans, D. Püntener, and A. Helenius, "Local actin polymerization and dynamin recruitment in SV40-induced internalization of caveolae," Science, vol. 296, no. 5567, pp. 535-539, 2002. 
[124] B. Tsai, J. M. Gilbert, T. Stehle, W. Lencer, T. L. Benjamin, and T. A. Rapoport, "Gangliosides are receptors for murine polyoma virus and SV40," EMBO Journal, vol. 22, no. 17, pp. 4346-4355, 2003.

[125] J. Gilbert, J. Dahl, C. Riney et al., "Ganglioside GD1a restores infectibility to mouse cells lacking functional receptors for polyomavirus," Journal of Virology, vol. 79, no. 1, pp. 615618, 2005.

[126] M. Schelhaas, J. Malmström, L. Pelkmans et al., "Simian virus 40 depends on ER protein folding and quality control factors for entry into host cells," Cell, vol. 131, no. 3, pp. 516-529, 2007.

[127] S. Gold, P. Monaghan, P. Mertens, and T. Jackson, "A clathrin independent macropinocytosis-like entry mechanism used by bluetongue virus-1 during infection of BHK cells," PLoS ONE, vol. 5, no. 6, Article ID e11360, 2010.

[128] C. A. Guerrero, S. Zarate, G. Corkidi, S. Lopez, and C. F. Arias, "Biochemical characterization of rotavirus receptors in MA104 cells," Journal of Virology, vol. 74, no. 20, pp. 93629371, 2000.

[129] C. F. Arias, P. Isa, C. A. Guerrero et al., "Molecular biology of rotavirus cell entry," Archives of Medical Research, vol. 33, no. 4, pp. 356-361, 2002.

[130] C. Sapin, O. Colard, O. Delmas et al., "Rafts promote assembly and atypical targeting of a nonenveloped virus, rotavirus, in Caco-2 cells," Journal of Virology, vol. 76, no. 9, pp. 45914602, 2002.

[131] M. C. Dechecchi, P. Melotti, A. Bonizzato, M. Santacatterina, M. Chilosi, and G. Cabrini, "Heparan sulfate glycosaminoglycans are receptors sufficient to mediate the initial binding of adenovirus types 2 and 5," Journal of Virology, vol. 75, no. 18 , pp. 8772-8780, 2001.

[132] J. M. Greve, G. Davis, A. M. Meyer et al., "The major human rhinovirus receptor is ICAM-1,” Cell, vol. 56, no. 5, pp. 839847, 1989.

[133] D. E. Staunton, V. J. Merluzzi, R. Rothlein, R. Barton, S. D. Marlin, and T. A. Springer, "A cell adhesion molecule, ICAM1 , is the major surface receptor for rhinoviruses," Cell, vol. 56, no. 5, pp. 849-853, 1989.

[134] J. Bella and M. G. Rossmann, "ICAM-1 receptors and cold viruses," Pharmaceutica Acta Helvetiae, vol. 74, no. 2-3, pp. 291-297, 2000.

[135] Z. Bacsó, L. Bene, L. Damjanovich, and S. Damjanovich, "INF- $\gamma$ rearranges membrane topography of MHC-I and ICAM-1 in colon carcinoma cells," Biochemical and Biophysical Research Communications, vol. 290, no. 2, pp. 635-640, 2002.

[136] B. E. Hoots, J. M. Palefsky, J. M. Pimenta, and J. S. Smith, "Human papillomavirus type distribution in anal cancer and anal intraepithelial lesions," International Journal of Cancer, vol. 124, no. 10, pp. 2375-2383, 2008.

[137] X. Yang, O. V. Kovalenko, W. Tang, C. Claas, C. S. Stipp, and M. E. Hemler, "Palmitoylation supports assembly and function of integrin-tetraspanin complexes," Journal of Cell Biology, vol. 167, no. 6, pp. 1231-1240, 2004.

[138] S. J. Israels and E. M. McMillan-Ward, "Platelet tetraspanin complexes and their association with lipid rafts," Thrombosis and Haemostasis, vol. 98, no. 5, pp. 1081-1087, 2007.

[139] A. J. Levine, "The common mechanisms of transformation by the small DNA tumor viruses: the inactivation of tumor suppressor gene products: p53," Virology, vol. 384, no. 2, pp. 285-293, 2009.
[140] T. V. Kurzchalia, P. Dupree, R. G. Parton et al., "VIP21, a $21-\mathrm{kD}$ membrane protein is an integral component of transGolgi- network-derived transport vesicles," Journal of Cell Biology, vol. 118, no. 5, pp. 1003-1014, 1992.

[141] K. G. Rothberg, J. E. Heuser, W. C. Donzell, Y. S. Ying, J. R. Glenney, and R. G. W. Anderson, "Caveolin, a protein component of caveolae membrane coats," Cell, vol. 68, no. 4, pp. 673-682, 1992.

[142] D. Liebl, F. Difato, L. Horníková, P. Mannová, J. Štokrová, and J. Forstová, "Mouse polyomavirus enters early endosomes, requires their acidic $\mathrm{pH}$ for productive infection, and meets transferrin cargo in Rab11-positive endosomes," Journal of Virology, vol. 80, no. 9, pp. 4610-4622, 2006.

[143] S. T. Shi, K. J. Lee, H. Aizaki, S. B. Hwang, and M. M. C. Lai, "Hepatitis C virus RNA replication occurs on a detergentresistant membrane that cofractionates with caveolin-2," Journal of Virology, vol. 77, no. 7, pp. 4160-4168, 2003.

[144] H. Aizaki, K. J. Lee, V. M. H. Sung, H. Ishiko, and M. M. C. Lai, "Characterization of the hepatitis C virus RNA replication complex associated with lipid rafts," Virology, vol. 324, no. 2, pp. 450-461, 2004.

[145] H. Sakamoto, K. Okamoto, M. Aoki et al., "Host sphingolipid biosynthesis as a target for hepatitis C virus therapy," Nature Chemical Biology, vol. 1, no. 6, pp. 333-337, 2005.

[146] L. Weng, Y. Hirata, M. Arai et al., "Sphingomyelin activates hepatitis C virus RNA polymerase in a genotype-specific manner," Journal of Virology, vol. 84, no. 22, pp. 1176111770, 2010.

[147] H. Aizaki, K. Morikawa, M. Fukasawa et al., "Critical role of virion-associated cholesterol and sphingolipid in hepatitis C virus infection," Journal of Virology, vol. 82, no. 12, pp. 57155724, 2008.

[148] S. Noisakran, T. Dechtawewat, P. Avirutnan et al., "Association of dengue virus NS1 protein with lipid rafts," Journal of General Virology, vol. 89, no. 10, pp. 2492-2500, 2008.

[149] B. M. Silva, L. P. Sousa, A. C. Gomes-Ruiz et al., "The dengue virus nonstructural protein 1 (NS1) increases NF- $\kappa$ B transcriptional activity in HepG2 cells," Archives of Virology, vol. 156, no. 7, pp. 1275-1279, 2011.

[150] T. P. McDonald, A. R. Pitt, G. Brown, H. W. M. Rixon, and R. J. Sugrue, "Evidence that the respiratory syncytial virus polymerase complex associates with lipid rafts in virus-infected cells: a proteomic analysis," Virology, vol. 330, no. 1, pp. 147-157, 2004.

[151] G. Brown, H. W. M. Rixon, J. Steel et al., "Evidence for an association between heat shock protein 70 and the respiratory syncytial virus polymerase complex within lipid-raft membranes during virus infection," Virology, vol. 338, no. 1, pp. 69-80, 2005.

[152] R. G. Panchal, G. Ruthel, T. A. Kenny et al., "In vivo oligomerization and raft localization of Ebola virus protein VP40 during vesicular budding," Proceedings of the National Academy of Sciences of the United States of America, vol. 100, no. 26, pp. 15936-15941, 2003.

[153] R. Hasebe, T. Suzuki, Y. Makino et al., "Transcellular transport of West Nile virus-like particles across human endothelial cells depends on residues 156 and 159 of envelope protein," BMC Microbiology, vol. 10, p. 165, 2010.

[154] E. L. Sharp, N. J. Davis-Poynter, and H. E. Farrell, "Analysis of the subcellular trafficking properties of murine cytomegalovirus M78, a 7 transmembrane receptor homologue," Journal of General Virology, vol. 90, no. 1, pp. 59-68, 2009. 
[155] G. E. Lee, G. A. Church, and D. W. Wilson, "A subpopulation of tegument protein vhs localizes to detergent-insoluble lipid rafts in herpes simplex virus-infected cells," Journal of Virology, vol. 77, no. 3, pp. 2038-2045, 2003.

[156] T. Koshizuka, Y. Kawaguchi, N. Nozawa, I. Mori, and Y. Nishiyama, "Herpes simplex virus protein UL11 but not UL51 is associated with lipid rafts," Virus Genes, vol. 35, no. 3, pp. 571-575, 2007.

[157] A. Kawabata, H. Tang, H. Huang, K. Yamanishi, and Y. Mori, "Human herpesvirus 6 envelope components enriched in lipid rafts: evidence for virion-associated lipid rafts," Virology Journal, vol. 6, article 127, 2009.

[158] P. Keller and K. Simons, "Cholesterol is required for surface transport of influenza virus hemagglutinin," Journal of Cell Biology, vol. 140, no. 6, pp. 1357-1367, 1998.

[159] P. Scheiffele, A. Rietveld, T. Wilk, and K. Simons, "Influenza viruses select ordered lipid domains during budding from the plasma membrane," Journal of Biological Chemistry, vol. 274, no. 4, pp. 2038-2044, 1999.

[160] S. Barman and D. P. Nayak, "Analysis of the transmembrane domain of influenza virus neuraminidase, a type II transmembrane glycoprotein, for apical sorting and raft association," Journal of Virology, vol. 74, no. 14, pp. 6538-6545, 2000.

[161] S. Heino, S. Lusa, P. Somerharju, C. Ehnholm, V. M. Olkkonen, and E. Ikonen, "Dissecting the role of the Golgi complex and lipid rafts in biosynthetic transport of cholesterol to the cell surface," Proceedings of the National Academy of Sciences of the United States of America, vol. 97, no. 15, pp. 8375-8380, 2000.

[162] J. Zhang, A. Pekosz, and R. A. Lamb, "Influenza virus assembly and lipid raft microdomains: a role for the cytoplasmic tails of the spike glycoproteins," Journal of Virology, vol. 74, no. 10, pp. 4634-4644, 2000.

[163] S. Barman, L. Adhikary, A. K. Chakrabarti, C. Bernas, Y. Kawaoka, and D. P. Nayak, "Role of transmembrane domain and cytoplasmic tail amino acid sequences of influenza A virus neuraminidase in raft association and virus budding," Journal of Virology, vol. 78, no. 10, pp. 5258-5269, 2004.

[164] M. Carrasco, M. J. Amorim, and P. Digard, "Lipid raft-dependent targeting of the influenza A virus nucleoprotein to the apical plasma membrane," Traffic, vol. 5, no. 12, pp. 979992, 2004.

[165] G. P. Leser and R. A. Lamb, "Influenza virus assembly and budding in raft-derived microdomains: a quantitative analysis of the surface distribution of HA, NA and M2 proteins," Virology, vol. 342, no. 2, pp. 215-227, 2005.

[166] H. Marjuki, M. I. Alam, C. Ehrhardt et al., "Membrane accumulation of influenza A virus hemagglutinin triggers nuclear export of the viral genome via protein kinase $\mathrm{C} \alpha$ mediated activation of ERK signaling," Journal of Biological Chemistry, vol. 281, no. 24, pp. 16707-16715, 2006.

[167] B. J. Chen, G. P. Leser, E. Morita, and R. A. Lamb, "Influenza virus hemagglutinin and neuraminidase, but not the matrix protein, are required for assembly and budding of plasmidderived virus-like particles," Journal of Virology, vol. 81, no. 13, pp. 7111-7123, 2007

[168] S. Barman and D. P. Nayak, "Lipid raft disruption by cholesterol depletion enhances influenza A virus budding from MDCK cells," Journal of Virology, vol. 81, no. 22, pp. 12169 12178, 2007.
[169] J. S. Rossman, X. Jing, G. P. Leser, V. Balannik, L. H. Pinto, and R. A. Lamb, "Influenza virus M2 ion channel protein is necessary for filamentous virion formation," Journal of Virology, vol. 84, no. 10, pp. 5078-5088, 2010.

[170] B. Thaa, A. Herrmann, and M. Veit, "Intrinsic cytoskeletondependent clustering of influenza virus M2 protein with hemagglutinin assessed by FLIM-FRET," Journal of Virology, vol. 84, no. 23, pp. 12445-12449, 2010.

[171] B. Thaa, I. Levental, A. Herrmann, and M. Veit, "Intrinsic membrane association of the cytoplasmic tail of influenza virus $\mathrm{M} 2$ protein and lateral membrane sorting regulated by cholesterol binding and palmitoylation," Biochemical Journal, vol. 437, no. 3, pp. 389-397, 2011.

[172] S. N. Manié, S. de Breyne, S. Vincent, and D. Gerlier, "Measles virus structural components are enriched into lipid raft microdomains: a potential cellular location for virus assembly," Journal of Virology, vol. 77, pp. 13389-13395, 2003.

[173] S. Vincent, D. Gerlier, and S. N. Manie, "Measles virus assembly within membrane rafts," Journal of Virology, vol. 74, no. 21, pp. 9911-9915, 2000.

[174] J. P. Laliberte, L. W. McGinnes, M. E. Peeples, and T. G. Morrison, "Integrity of membrane lipid rafts is necessary for the ordered assembly and release of infectious Newcastle disease virus particles," Journal of Virology, vol. 80, no. 21, pp. 1065210662, 2006.

[175] J. P. Laliberte, L. W. McGinnes, and T. G. Morrison, "Incorporation of functional HN-F glycoprotein-containing complexes into Newcastle disease virus is dependent on cholesterol and membrane lipid raft integrity," Journal of Virology, vol. 81, no. 19, pp. 10636-10648, 2007.

[176] G. Brown, H. W. M. Rixon, and R. J. Sugrue, "Respiratory syncytial virus assembly occurs in GM1-rich regions of the host-cell membrane and alters the cellular distribution of tyrosine phosphorylated caveolin-1," Journal of General Viro$\log y$, vol. 83, no. 8, pp. 1841-1850, 2002.

[177] A. Marty, J. Meanger, J. Mills, B. Shields, and R. Ghildyal, "Association of matrix protein of respiratory syncytial virus with the host cell membrane of infected cells," Archives of Virology, vol. 149, no. 1, pp. 199-210, 2004.

[178] A. G. P. Oomens, K. P. Bevis, and G. W. Wertz, “The cytoplasmic tail of the human respiratory syncytial virus F protein plays critical roles in cellular localization of the $\mathrm{F}$ protein and infectious progeny production," Journal of Virology, vol. 80, no. 21, pp. 10465-10477, 2006.

[179] D. S. Y. Yeo, R. Chan, G. Brown et al., "Evidence that selective changes in the lipid composition of raft-membranes occur during respiratory syncytial virus infection," Virology, vol. 386, no. 1, pp. 168-182, 2009.

[180] A. Ali and D. P. Nayak, "Assembly of Sendal virus: M protein interacts with $\mathrm{F}$ and $\mathrm{HN}$ proteins and with the cytoplasmic tail and transmembrane domain of F protein," Virology, vol. 276, no. 2, pp. 289-303, 2000.

[181] A. S. Gosselin-Grenet, G. Mottet-Osman, and L. Roux, "From assembly to virus particle budding: pertinence of the detergent resistant membranes," Virology, vol. 344, no. 2, pp. 296-303, 2006.

[182] D. H. Nguyen and J. E. K. Hildreth, "Evidence for budding of human immunodeficiency virus type 1 selectively from glycolipid-enriched membrane lipid rafts," Journal of Virology, vol. 74, no. 7, pp. 3264-3272, 2000.

[183] R. Welker, M. Harris, B. Cardel, and H. G. Kräusslich, "Virion incorporation of human immunodeficiency virus type $1 \mathrm{Nef}$ 
is mediated by a bipartite membrane-targeting signal: analysis of its role in enhancement of viral infectivity," Journal of Virology, vol. 72, no. 11, pp. 8833-8840, 1998.

[184] J. K. Wang, E. Kiyokawa, E. Verdin, and D. Trono, “The Nef protein of HIV-1 associates with rafts and primes T cells for activation," Proceedings of the National Academy of Sciences of the United States of America, vol. 97, no. 1, pp. 394-399, 2000.

[185] D. J. Wyma, A. Kotov, and C. Aiken, "Evidence for a stable interaction of gp41 with Pr55(Gag) in immature human immunodeficiency virus type 1 particles," Journal of Virology, vol. 74, no. 20, pp. 9381-9387, 2000.

[186] O. W. Lindwasser and M. D. Resh, "Multimerization of human immunodeficiency virus type $1 \mathrm{Gag}$ promotes its localization to barges, raft-like membrane microdomains," Journal of Virology, vol. 75, no. 17, pp. 7913-7924, 2001.

[187] Y. H. Zheng, A. Plemenitas, T. Linnemann, O. T. Fackler, and B. M. Peterlin, "Nef increases infectivity of HIV via lipid rafts," Current Biology, vol. 11, no. 11, pp. 875-879, 2001.

[188] A. Ono and E. O. Freed, "Plasma membrane rafts play a critical role in HIV-1 assembly and release," Proceedings of the National Academy of Sciences of the United States of America, vol. 98, no. 24, pp. 13925-13930, 2001.

[189] J. Bhattacharya, P. J. Peters, and P. R. Clapham, "Human immunodeficiency virus type 1 envelope glycoproteins that lack cytoplasmic domain cysteines: impact on association with membrane lipid rafts and incorporation onto budding virus particles," Journal of Virology, vol. 78, no. 10, pp. 55005506, 2004.

[190] A. Ono, A. A. Waheed, A. Joshi, and E. O. Freed, "Association of human immunodeficiency virus type 1 Gag with membrane does not require highly basic sequences in the nucleocapsid: use of a novel Gag multimerization assay," Journal of Virology, vol. 79, no. 22, pp. 14131-14140, 2005.

[191] S. I. Giese, I. Woerz, S. Homann, N. Tibroni, M. Geyer, and O. T. Fackler, "Specific and distinct determinants mediate membrane binding and lipid raft incorporation of HIV-1SF2 Nef," Virology, vol. 355, no. 2, pp. 175-191, 2006.

[192] B. Brügger, E. Krautkrämer, N. Tibroni et al., "Human immunodeficiency virus type 1 Nef protein modulates the lipid composition of virions and host cell membrane microdomains," Retrovirology, vol. 4, article 70, 2007.

[193] A. Ono, A. A. Waheed, and E. O. Freed, "Depletion of cellular cholesterol inhibits membrane binding and higher-order multimerization of human immunodeficiency virus type 1 Gag," Virology, vol. 360, no. 1, pp. 27-35, 2007.

[194] K. Leung, J. O. Kim, L. Ganesh, J. Kabat, O. Schwartz, and G. J. Nabel, "HIV-1 assembly: viral glycoproteins segregate quantally to lipid rafts that associate individually with HIV-1 capsids and virions," Cell Host and Microbe, vol. 3, no. 5, pp. 285-292, 2008.

[195] M. A. Khan, R. Goila-Gaur, S. Kao, E. Miyagi, R. C. Walker, and K. Strebel, "Encapsidation of APOBEC3G into HIV-1 virions involves lipid raft association and does not correlate with APOBEC3G oligomerization," Retrovirology, vol. 6, article 1742, p. 99, 2009.

[196] A. V. Harrist, E. V. Ryzhova, T. Harvey, and F. González-Scarano, "Anx2 interacts with HIV-1 Gag at phosphatidylinositol $(4,5)$ bisphosphate-containing lipid rafts and increases viral production in 293 T cells," PLoS ONE, vol. 4, no. 3, Article ID e5020, 2009.

[197] D. N. Krementsov, P. Rassam, E. Margeat et al., "HIV-1 assembly differentially alters dynamics and partitioning of tetraspanins and raft components," Traffic, vol. 11, no. 11, pp. 1401-1414, 2010.
[198] S. Lin, X. M. Wang, P. E. Nadeau, and A. Mergia, "HIV infection upregulates caveolin 1 expression to restrict virus production," Journal of Virology, vol. 84, no. 18, pp. 9487-9496, 2010.

[199] B. D. Kuhl, R. D. Sloan, D. A. Donahue, T. Bar-Magen, C. Liang, and M. A. Wainberg, "Tetherin restricts direct cellto-cell infection of HIV-1," Retrovirology, vol. 7, article 115, 2010.

[200] A. Ruiz, M. S. Hill, K. Schmitt, and E. B. Stephens, "Membrane raft association of the Vpu protein of human immunodeficiency virus type 1 correlates with enhanced virus release," Virology, vol. 408, no. 1, pp. 89-102, 2010.

[201] J. Ma, X. Li, J. Xu et al., "The cellular source for APOBEC3G's incorporation into HIV-1," Retrovirology, vol. 8, p. 2, 2011.

[202] X. Feng, N. Vander Heyden, and L. Ratner, "Alpha interferon inhibits human T-cell leukemia virus type 1 assembly by preventing Gag interaction with rafts," Journal of Virology, vol. 77, no. 24, pp. 13389-13395, 2003.

[203] W. F. Odenwald, H. Arnheiter, M. Dubois-Dalcq, and R. A. Lazzarini, "Stereo images of vesicular stomatitis virus assembly," Journal of Virology, vol. 57, no. 3, pp. 922-932, 1986.

[204] E. L. Brown and D. S. Lyles, "A novel method for analysis of membrane microdomains: vesicular stomatitis virus glycoprotein microdomains change in size during infection, and those outside of budding sites resemble sites of virus budding," Virology, vol. 310, no. 2, pp. 343-358, 2003.

[205] R. J. Sugrue, R. B. Belshe, and A. J. Hay, "Palmitoylation of the influenza A virus M2 protein,” Virology, vol. 179, no. 1, pp. 51-56, 1990.

[206] K. H. Cheong, D. Zacchetti, E. E. Schneeberger, and K. Simons, "VIP17/MAL, a lipid raft-associated protein, is involved in apical transport in MDCK cells," Proceedings of the National Academy of Sciences of the United States of America, vol. 96, no. 11, pp. 6241-6248, 1999.

[207] B. J. Chen, G. P. Leser, D. Jackson, and R. A. Lamb, "The influenza virus $\mathrm{M} 2$ protein cytoplasmic tail interacts with the M1 protein and influences virus assembly at the site of virus budding," Journal of Virology, vol. 82, no. 20, pp. 1005910070, 2008.

[208] I. Mena, A. Vivo, E. Pérez, and A. Portela, "Rescue of a synthetic chloramphenicol acetyltransferase RNA into influenza virus-like particles obtained from recombinant plasmids," Journal of Virology, vol. 70, no. 8, pp. 5016-5024, 1996.

[209] P. Gómez-Puertas, C. Albo, E. Pérez-Pastrana, A. Vivo, and A. Portela, "Influenza virus matrix protein is the major driving force in virus budding," Journal of Virology, vol. 74, no. 24, pp. 11538-11547, 2000.

[210] T. Takahashi, K. Murakami, M. Nagakura et al., "Sulfatide is required for efficient replication of influenza A virus," Journal of Virology, vol. 82, no. 12, pp. 5940-5950, 2008.

[211] D. N. Arvanitis, W. Min, Y. Gong, Y. M. Heng, and J. M. Boggs, "Two types of detergent-insoluble, glycosphingolipid/cholesterol-rich membrane domains from isolated myelin," Journal of Neurochemistry, vol. 94, no. 6, pp. 16961710, 2005.

[212] D. Lingwood, G. Harauz, and J. S. Ballantyne, "Regulation of fish gill $\mathrm{Na}^{+}-\mathrm{K}^{+}$-ATPase by selective sulfatide-enriched raft partitioning during seawater adaptation," Journal of Biological Chemistry, vol. 280, no. 44, pp. 36545-36550, 2005.

[213] M. Caballero, J. Carabaña, J. Ortego, R. Fernández-Muñoz, and M. L. Celma, "Measles virus fusion protein is palmitoylated on transmembrane- intracytoplasmic cysteine residues which participate in cell fusion," Journal of Virology, vol. 72, no. 10, pp. 8198-8204, 1998. 
[214] O. W. Lindwasser and M. D. Resh, "Myristoylation as a target for inhibiting HIV assembly: unsaturated fatty acids block viral budding," Proceedings of the National Academy of Sciences of the United States of America, vol. 99, no. 20, pp. 13037-13042, 2002.

[215] M. T. K. Mulari, M. Nars, T. Laitala-Leinonen et al., "Recombinant VSV G proteins reveal a novel raft-dependent endocytic pathway in resorbing osteoclasts," Experimental Cell Research, vol. 314, no. 8, pp. 1641-1651, 2008.

[216] B. Bhattacharya and P. Roy, "Bluetongue virus outer capsid protein VP5 interacts with membrane lipid rafts via a SNARE domain," Journal of Virology, vol. 82, no. 21, pp. 1060010612, 2008.

[217] M. A. Cuadras and H. B. Greenberg, "Rotavirus infectious particles use lipid rafts during replication for transport to the cell surface in vitro and in vivo," Virology, vol. 313, no. 1, pp. 308-321, 2003.

[218] O. Delmas, A. M. Durand-Schneider, J. Cohen, O. Colard, and G. Trugnan, "Spike protein VP4 assembly with maturing rotavirus requires a postendoplasmic reticulum event in polarized caco-2 cells," Journal of Virology, vol. 78, no. 20, pp. 10987-10994, 2004.

[219] O. Delmas, M. Breton, C. Sapin, A. Le Bivic, O. Colard, and G. Trugnan, "Heterogeneity of raft-type membrane microdomains associated with VP4, the rotavirus spike protein, in Caco-2 and MA 104 cells," Journal of Virology, vol. 81, no. 4, pp. 1610-1618, 2007.

[220] S. M. Storey, T. F. Gibbons, C. V. Williams, R. D. Parr, F. Schroeder, and J. M. Ball, "Full-length, glycosylated NSP4 is localized to plasma membrane caveolae by a novel raft isolation technique," Journal of Virology, vol. 81, no. 11, pp. 5472-5483, 2007.

[221] J. Huang, T. Ren, H. Guan, Y. Jiang, and H. Cheng, "HTLV-1 tax is a critical lipid raft modulator that hijacks $I \kappa B$ kinases to the microdomains for persistent activation of NF- $\kappa \mathrm{B}$," Journal of Biological Chemistry, vol. 284, no. 10, pp. 62086217, 2009.

[222] C.-J. Chen, Y.-C. Ou, C.-Y. Chang et al., "Src signaling involvement in Japanese encephalitis virus-induced cytokine production in microglia," Neurochemistry International, vol. 58, no. 8, pp. 924-933, 2011.

[223] A. Ghannam, D. Hammache, C. Matias, M. Louwagie, J. Garin, and D. Gerlier, "High-density rafts preferentially host the complement activator measles virus F glycoprotein but not the regulators of complement activation," Molecular Immunology, vol. 45, no. 11, pp. 3036-3044, 2008.

[224] E. Avota, N. Müller, M. Klett, and S. Schneider-Schaulies, "Measles virus interacts with and alters signal transduction in T-cell lipid rafts," Journal of Virology, vol. 78, no. 17, pp. 9552-9559, 2004.

[225] J. M. Hill, I. Steiner, K. E. Matthews, S. G. Trahan, T. P. Foster, and M. J. Ball, "Statins lower the risk of developing Alzheimer's disease by limiting lipid raft endocytosis and decreasing the neuronal spread of Herpes simplex virus type 1," Medical Hypotheses, vol. 64, no. 1, pp. 53-58, 2005.

[226] C. J. Carter, "Interactions between the products of the Herpes simplex genome and Alzheimer's disease susceptibility genes: relevance to pathological-signalling cascades," Neurochemistry International, vol. 52, no. 6, pp. 920-934, 2008.

[227] C -K. Min, S.-Y. Bang, B.-A. Cho et al., "Role of amphipathic helix of a herpesviral protein in membrane deformation and T cell receptor downregulation," PLoS Pathogens, vol. 4, no. 11, article e1000209, 2008.
[228] V. G. Anania and L. Coscoy, "Palmitoylation of MIR2 is required for its function," Journal of Virology, vol. 85, no. 5, pp. 2288-2295, 2011.

[229] M. L. Moore, M. H. Chi, K. Goleniewska, J. E. Durbin, and R. S. Peebles, "Differential regulation of GM1 and asialoGM1 expression by $\mathrm{T}$ cells and natural killer (NK) cells in respiratory syncytial virus infection," Viral Immunology, vol. 21, no. 3, pp. 327-338, 2008.

[230] T. Ebihara, M. Shingai, M. Matsumoto, T. Wakita, and T. Seya, "Hepatitis C virus-infected hepatocytes extrinsically modulate dendritic cell maturation to activate $\mathrm{T}$ cells and natural killer cells," Hepatology, vol. 48, no. 1, pp. 48-58, 2008.

[231] D. Petrovic, Z. Stamataki, E. Dempsey et al., "Hepatitis C virus targets the $\mathrm{T}$ cell secretory machinery as a mechanism of immune evasion," Hepatology, vol. 53, no. 6, pp. 18461853, 2011.

[232] Y. T. Fang, C. F. Lin, P. C. Liao et al., "Annexin A2 on lung epithelial cell surface is recognized by severe acute respiratory syndrome-associated coronavirus spike domain 2 antibodies," Molecular Immunology, vol. 47, no. 5, pp. 10001009, 2010.

[233] J. K. Bentley, D. C. Newcomb, A. M. Goldsmith, Y. Jia, U. S. Sajjan, and M. B. Hershenson, "Rhinovirus activates interleukin-8 expression via a Src/p110 $\beta$ phosphatidylinositol 3-kinase/Akt pathway in human airway epithelial cells," Journal of Virology, vol. 81, no. 3, pp. 1186-1194, 2007.

[234] H. L. Howie, R. A. Katzenellenbogen, and D. A. Galloway, "Papillomavirus E6 proteins," Virology, vol. 384, no. 2, pp. 324-334, 2009.

[235] F. A. Suprynowicz, G. L. Disbrow, E. Krawczyk, V. Simic, K. Lantzky, and R. Schlegel, "HPV-16 E5 oncoprotein upregulates lipid raft components caveolin-1 and ganglioside GM1 at the plasma membrane of cervical cells," Oncogene, vol. 27, no. 8, pp. 1071-1078, 2008.

[236] N. Naslavsky, R. Stein, A. Yanai, G. Friedlander, and A. Taraboulos, "Characterization of detergent-insoluble complexes containing the cellular prion protein and its scrapie isoform," Journal of Biological Chemistry, vol. 272, no. 10, pp. 6324-6331, 1997.

[237] D. Sarnataro, V. Campana, S. Paladino, M. Stornaiuolo, L. Nitsch, and C. Zurzolo, " $\mathrm{PrP}^{C}$ association with lipid rafts in the early secretory pathway stabilizes its cellular conformation," Molecular Biology of the Cell, vol. 15, no. 9, pp. 40314042, 2004.

[238] S. Gilch, C. Kehler, and H. M. Schätzl, "The prion protein requires cholesterol for cell surface localization," Molecular and Cellular Neuroscience, vol. 31, no. 2, pp. 346-353, 2006.

[239] D. Avrahami, Y. Dayan-Amouyal, S. Tal et al., "Virus-induced alterations of membrane lipids affect the incorporation of $\mathrm{PrP}^{\mathrm{Sc}}$ into cells," Journal of Neuroscience Research, vol. 86, no. 12, pp. 2753-2762, 2008.

[240] J. S. Wadia, M. Schaller, R. A. Williamson, and S. F. Dowdy, "Pathologic prion protein infects cells by lipid-raft dependent macropinocytosis," PLoS ONE, vol. 3, no. 10, Article ID e3314, 2008.

[241] Y. S. Kang, X. Zhao, J. Lovaas, E. Eisenberg, and L. E. Greene, "Clathrin-independent internalization of normal cellular prion protein in neuroblastoma cells is associated with the Arf6 pathway," Journal of Cell Science, vol. 122, no. 22, pp. 4062-4069, 2009.

[242] D. Sarnataro, A. Caputo, P. Casanova et al., "Lipid rafts and clathrin cooperate in the internalization of PrPC in epithelial FRT cells," PLoS ONE, vol. 4, no. 6, Article ID e5829, 2009. 
[243] D. R. Taylor, I. J. Whitehouse, and N. M. Hooper, "Glypican-1 mediates both prion protein lipid raft association and disease isoform formation," PLoS Pathogens, vol. 5, no. 11, article e1000666, 2009.

[244] V. Mattei, M. G. Barenco, V. Tasciotti et al., "Paracrine diffusion of PrPc and propagation of prion infectivity by plasma membrane-derived microvesicles," PLoS ONE, vol. 4, no. 4, article e5057, 2009.

[245] C. Bate, M. Tayebi, and A. Williams, "The glycosylphosphatidylinositol anchor is a major determinant of prion binding and replication," Biochemical Journal, vol. 428, no. 1, pp. 95-101, 2010. 

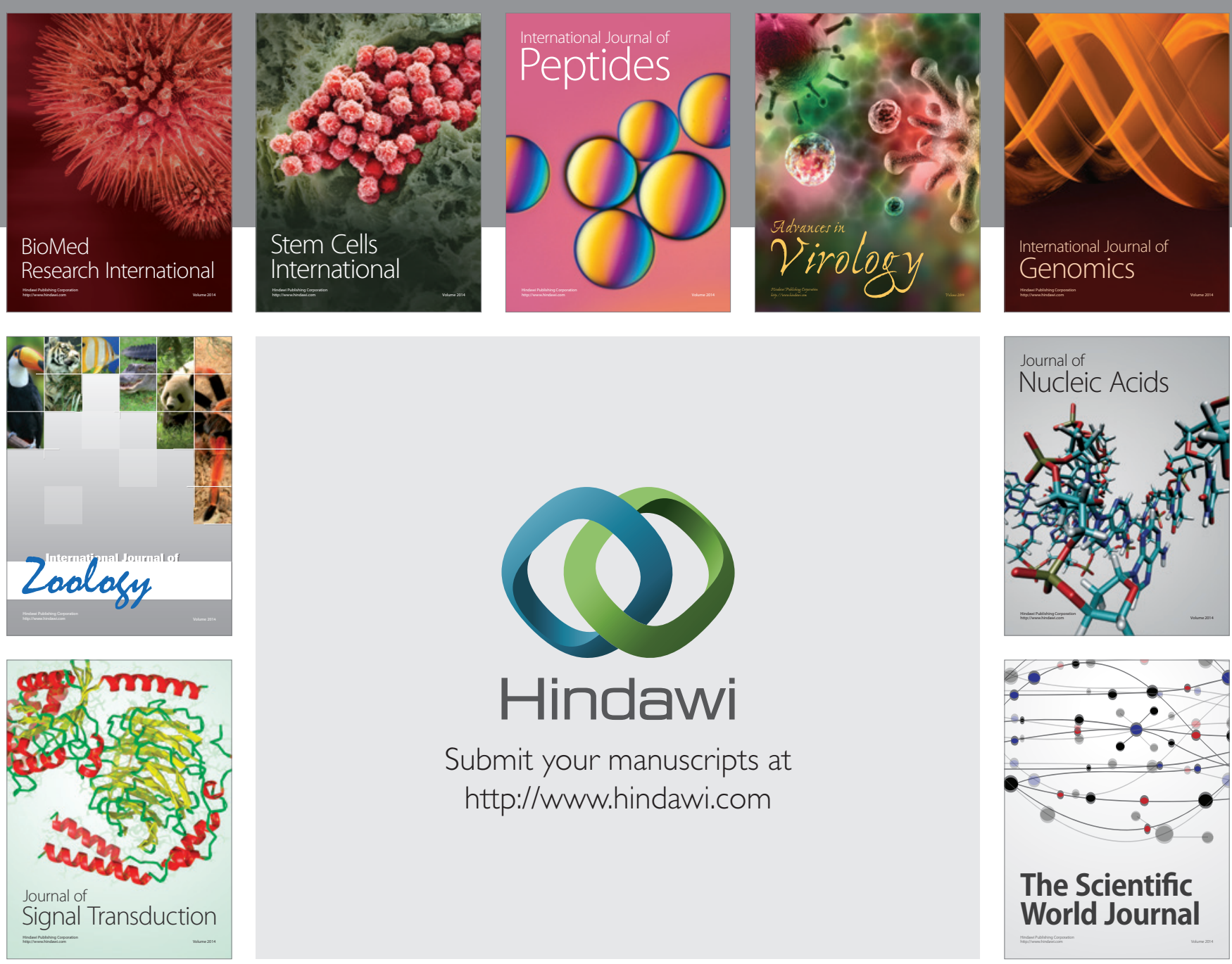

Submit your manuscripts at

http://www.hindawi.com
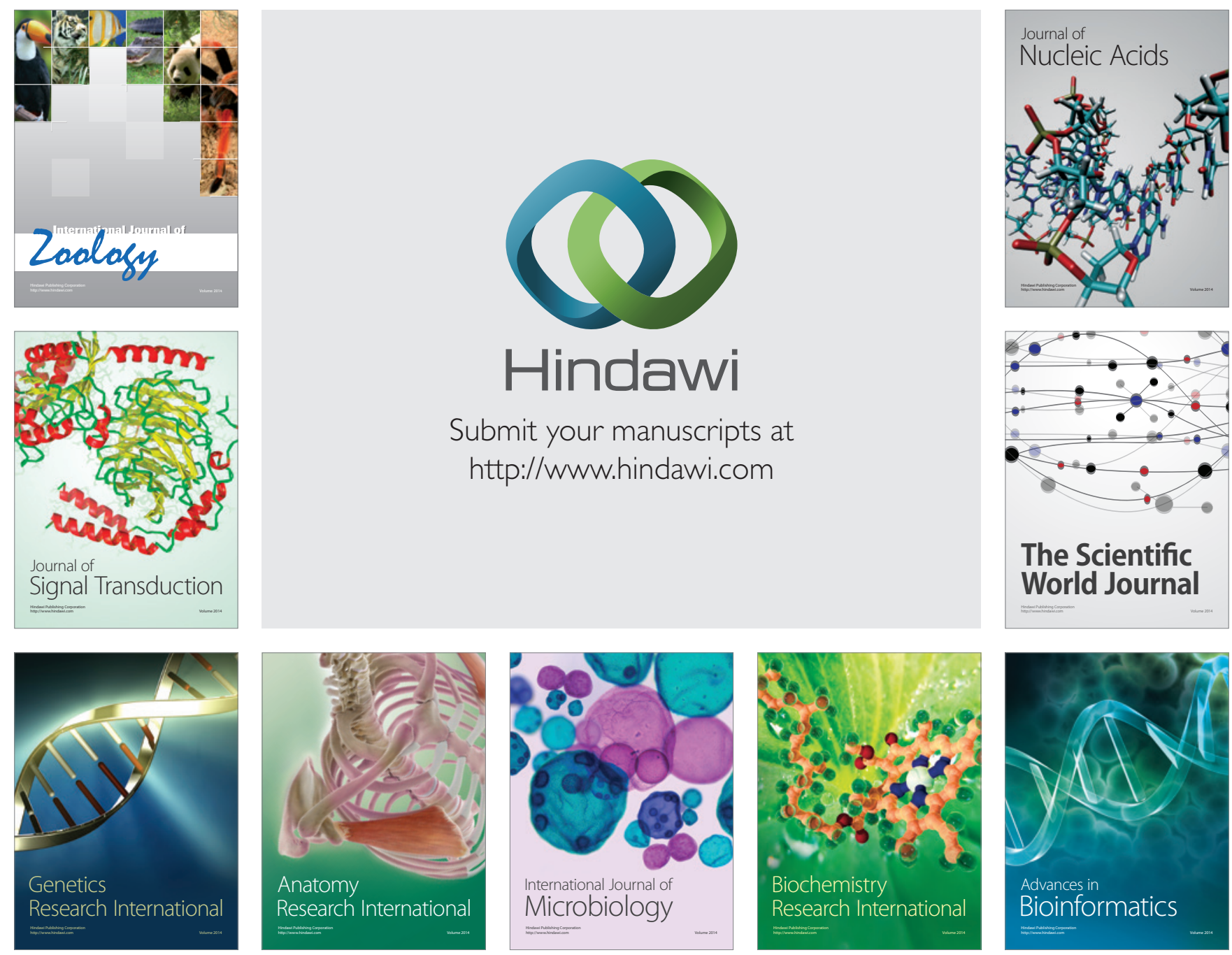

The Scientific World Journal
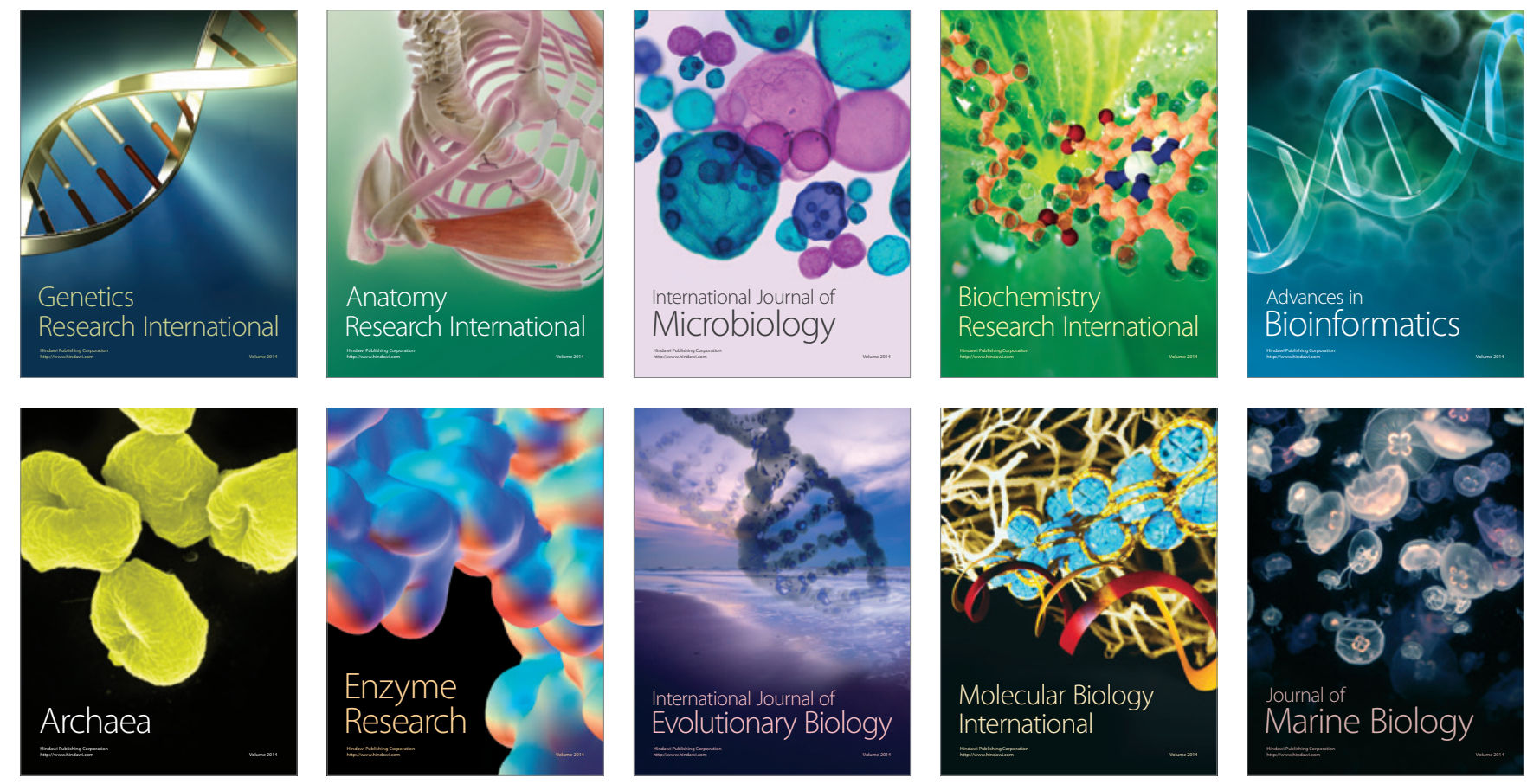